\title{
La figuración del paisaje de Cholula a través de la mirada de Alexander von Humboldt: reflexiones sobre su transformación territorial y socio-cultural
}

\author{
THE FIGURATION OF CHOLULA'S LANDSCAPE THROUGH THE GAZE OF \\ ALEXANDER VON HUMBOLDT: REFLECTIONS ON ITS TERRITORIAL AND \\ SOCIO-CULTURAL TRANSFORMATION
}
A FIGURAÇÃO DA PAISAGEM DE CHOLULA PELO OLHAR DE ALEXANDER VON HUMBOLDT: REFLEXÕES SOBRE SUA TRANSFORMAÇÃO TERRITORIAL E SOCIOCULTURAL

Melissa Schumacher *1

Anne K. Kurjenoja *

melissa.schumacher@udlap.mx

annek.kurjenoja@udlap.mx

\section{Resumen}

En 1894, Alexander von Humboldt realizó una serie de mediciones desde lo alto de la Gran Pirámide Tlachihualtépetl en Cholula. La visión que tuvo Humboldt sobre el paisaje le inspiró tal "respeto" que quedó plasmado en sus crónicas de viaje por América. Humboldt fue pionero en integrar la geobotánica como una herramienta de análisis visual y paisajístico, entendiendo la unidad de la naturaleza como un "todo" con diferentes escalas y planos de análisis. Por ello, esta investigación utiliza elementos del Naturgemälde de Humboldt y los Sistemas Socio-ecológicos del Paisaje (SES) para describir la transformación física que ha tenido el paisaje ru-urbano de Cholula. Para figurarlo, se presenta un análisis gráfico de diferentes tejidos que yuxtaponen el territorio de Cholula. Este trabajo observa cómo el espíritu humboldtiano está ejemplificado en Cholula, donde se debe reconocer el territorio desde lo biocultural, comprendiendo así la totalidad de la unidad en el microcosmos de Humboldt.

Palabras clave: paisaje ru-urbano, Cholula, Natürgemälde, Alexander von Humboldt

\footnotetext{
Abstract

$1 *$ Departamento de Arquitectura, Universidad de las Américas Puebla 
In 1894, Alexander von Humboldt made a series of measurements from the top of the Great Tlachihualtépetl Pyramid in Cholula. Humboldt's vision of landscape inspired such "respect" in him that it was featured in his travel chronicles through the American continent. Humboldt was a pioneer in integrating geo-botany as a visual and landscape analysis tool, understanding the unity of nature as a "whole" with different scales and levels of analysis. For this reason, this article uses elements of Humboldt's Naturgemälde and those of Socio-ecological System of landscape (SES) to describe the physical transformation of the ru-urban landscape of Cholula. To represent this, a graphic analysis of different tissues that juxtapose the territory of Cholula is presented. This work observes how the Humboldtian spirit is exemplified in Cholula, where the territory must be recognized from the biocultural point of view, thus understanding the totality of the unity in Humboldt's microcosm.

Keywords: ru-urban landscape, Cholula, Naturgemälde, Alexander von Humboldt

\section{Resumo}

Em 1894, Alexander von Humboldtó fez uma série de medições do topo da Grande Pirâmide Tlachihualtépetl em Cholula. A visão de Humboldt da paisagem inspirou-o com tanto "respeito" que se refletiu em suas crônicas de viagens pela América. Humboldt foi o pioneiro na integração da geobotânica como ferramenta de análise visual e paisagística, entendendo a unidade da natureza como um "todo" com diferentes escalas e planos de análise. Por esta razão, esta pesquisa usa elementos do Naturgemälde e Sistemas Ecológicos da Paisagem (SES) de Humboldt para descrever a transformação física que a paisagem ru-urbana de Cholula teve. Para descobrir isso, é apresentada uma análise gráfica de diferentes tecidos que justapõem o território de Cholula. Este trabalho avalia que o espírito humboldtiano é exemplificado em Cholula, onde o território deve ser reconhecido do ponto de vista biocultural, compreendendo assim a totalidade da unidade no microcosmo de Humboldt.

Palavras-chave: paisagem ru-urbano, Cholula, Natürgemälde, Alexander von Humboldt 


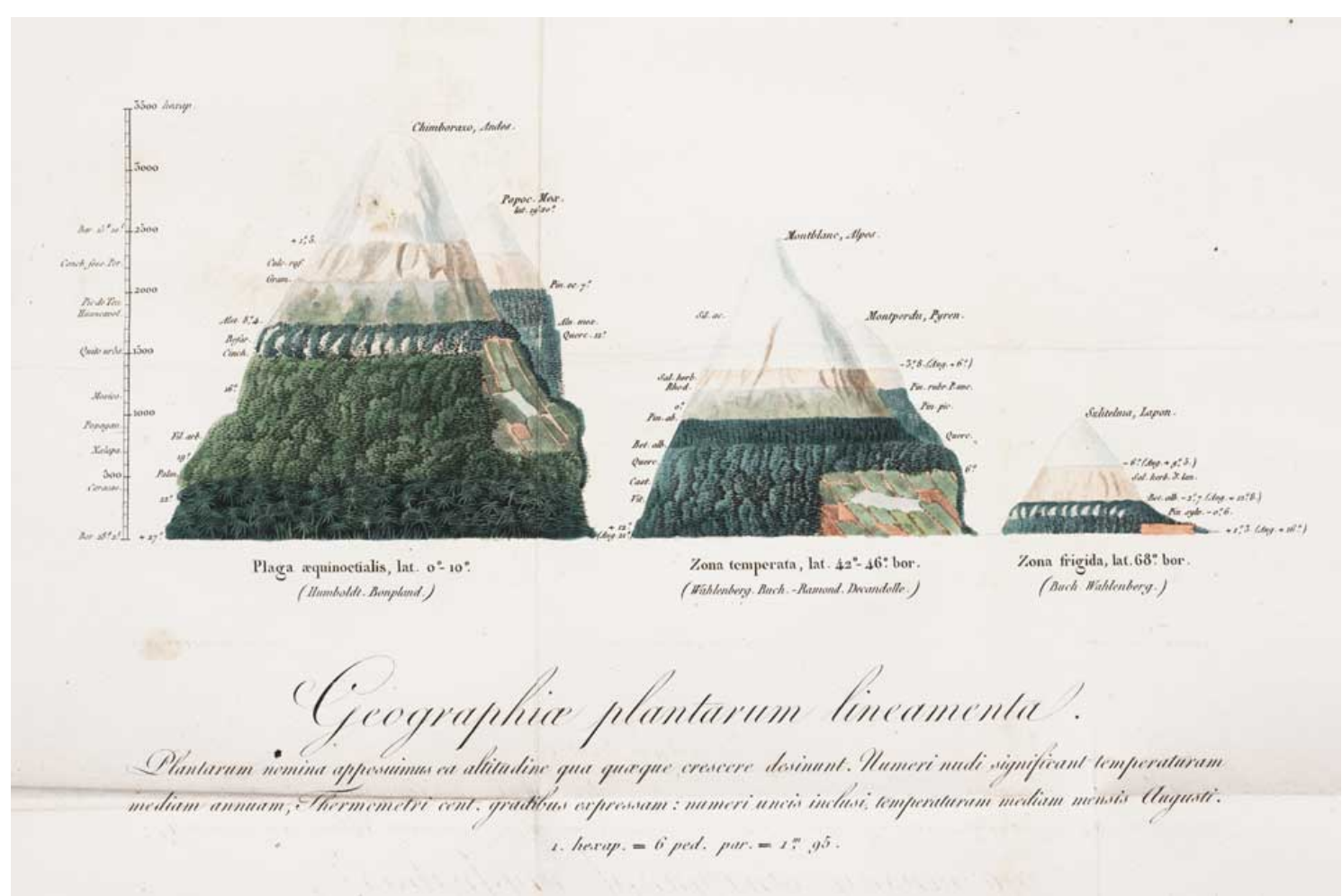

Figura 1. Alexander von Humboldt's illustration of Tropical, temperate, subarctic mountains" Von Humboldt A, Bonpland A. 2009 (1817). Essay on the Geography of Plants. Jackson ST, ed; Romanowski S, trans. University of Chicago Press.

\section{Introducción}

De 1799 a 1804, el naturalista Alexander von Humboldt y el botánico Aimé Bonpland realizaron un viaje extenso por varios países de América, entre ellos el territorio actual de México.

La importancia de Humboldt en su época -que trasciende a nuestros días-, se debió a que fue el primer científico "que abarcó la biología como un todo, como una red de relaciones que regía el comportamiento de cada parte y que comprendía los espacios y los tiempos" (Sampedro, 2016). Además, la curiosidad innata de Humboldt por conocer el extenso territorio americano permitió actualizar la cartografía de los antiguos territorios de la corona española que hoy en día comprenden el sur de Estados Unidos, Cuba, México, Venezuela, Colombia, Ecuador y Perú.

Es por ello que para Corberá Millán (2014), Humboldt también es reconocido como el primer ecologista y el primero en plasmar la "concepción paisajística de la geografía" donde se integran una perspectiva sensible (subjetiva) y otra analítica (objetiva) del paisaje (Corberá Millán, 2014, p.38). Además, como naturalista, "mostró por primera vez que la naturaleza era una fuerza global con zonas climáticas correspondientes en todos los continentes” (Wulf, 2016, p.116). 
En este contexto, esta investigación propone utilizar elementos de una de las herramientas gráficas desarrolladas por Humboldt: el cuadro gráfico del Naturgemälde para describir la transformación paisajística y cultural que ha tenido una de las ciudades que visitó Humboldt durante su paso por México, la ciudad de Cholula. Para representar dicha transformación, en este documento se refieren no solo los pasos de Humboldt por Cholula, sino también se describe la visión naturalista de la época que tanto influyó a Humboldt en la concepción del paisaje figurativo.

Debido a lo anterior, el estudio de Cholula ${ }^{2}$ es idóneo ya que presenta una propuesta de diferentes tejidos yuxtapuestos en su territorio como lo geográfico, usos de suelo, paisaje, y aspectos bioculturales y socioeconómicos. La adaptación del Naturgemälde, tomando como caso de estudio Cholula, demuestra como una herramienta gráfica complementado por la representación de los Sistemas Socio-ecológicos del Paisaje (SES), permite analizar la evolución rural-urbana (ru-urbana), y ser un instrumento clave para informar la resistencia socio-territorial ante el avance de la urbanización masiva de la zona. Dicho crecimiento pone en jaque la protección de un paisaje productivo histórico e intangible contra la homogeneización de la cultura local (Durán-Díaz, Armenta-Ramírez, Kurjenoja, \& Schumacher, 2020).

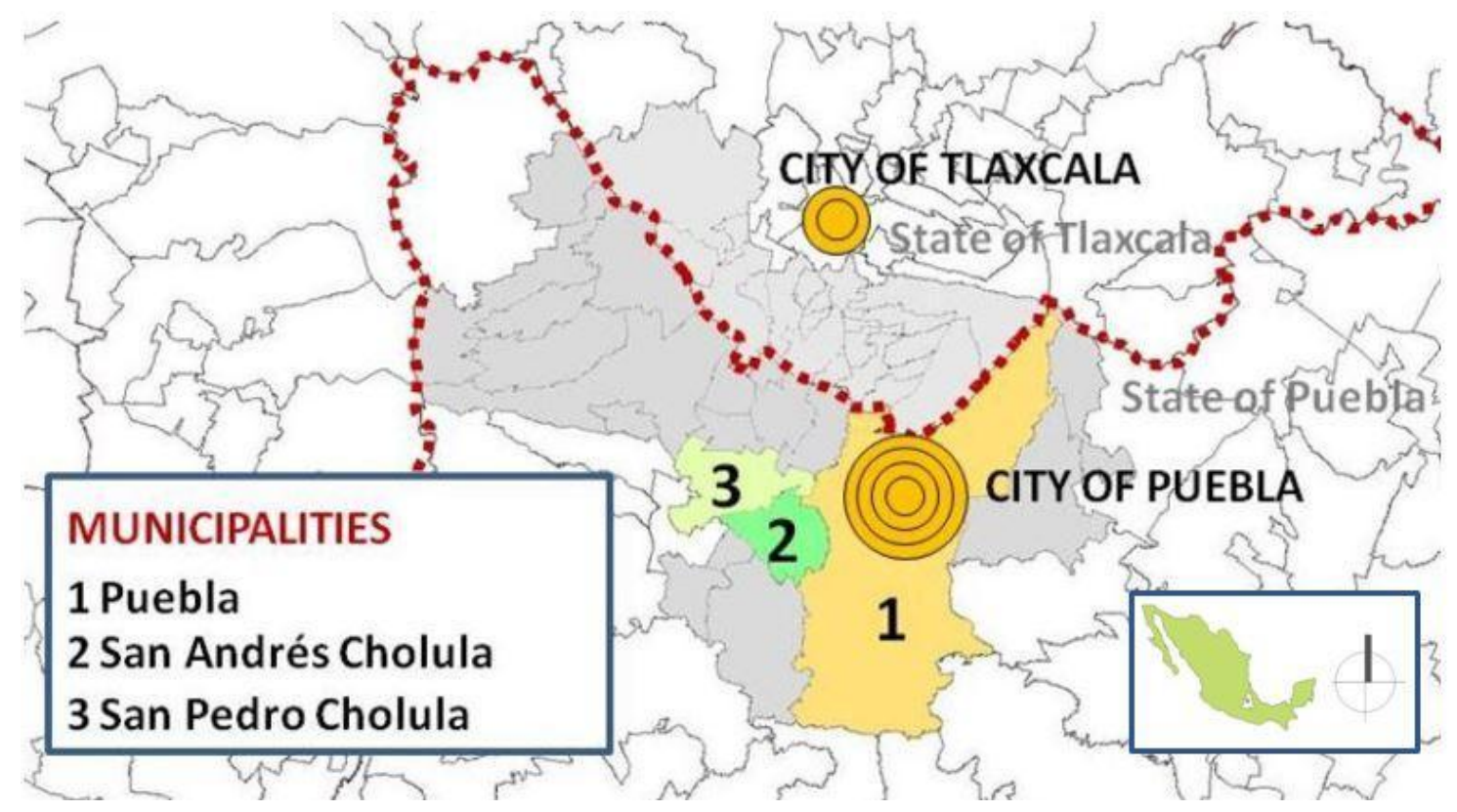

Figura 2. Mapa de ubicación de los municipios de San Andrés Cholula y San Pedro Cholula dentro de la Zona Metropolitana de Puebla-Tlaxcala. Fuente: elaborado por M. Schumacher (2015)

\footnotetext{
${ }^{2}$ El territorio cholulteca es hoy día compartido entre dos municipios, como se puede observar en el mapa de la Figura 2.: San Andrés y San Pedro Cholula.
} 


\section{Área de estudio}

Cuando Humboldt estuvo en México en 1804, fue en la ciudad de Cholula, localizada en el corazón del altiplano mexicano (figura 2) donde realizó una serie de mediciones y observaciones desde lo alto del Santuario de los Remedios y su Tlachihualtépetl, la Gran Pirámide. El paisaje que observó Humboldt en su momento, provisto de montañas, volcanes, llanos y milpas, ${ }^{3}$ no cambió durante varios siglos y la pequeña urbe cholulteca siguió manteniendo sus usos y costumbres hasta mediados del siglo XX. De origen, Cholula ${ }^{4}$ se define como un Altépetl vivo, es decir, una organización socio-espacial del territorio similar a otros tantos que dieron origen a muchas ciudades mesoamericanas (Reyes García, 1976).

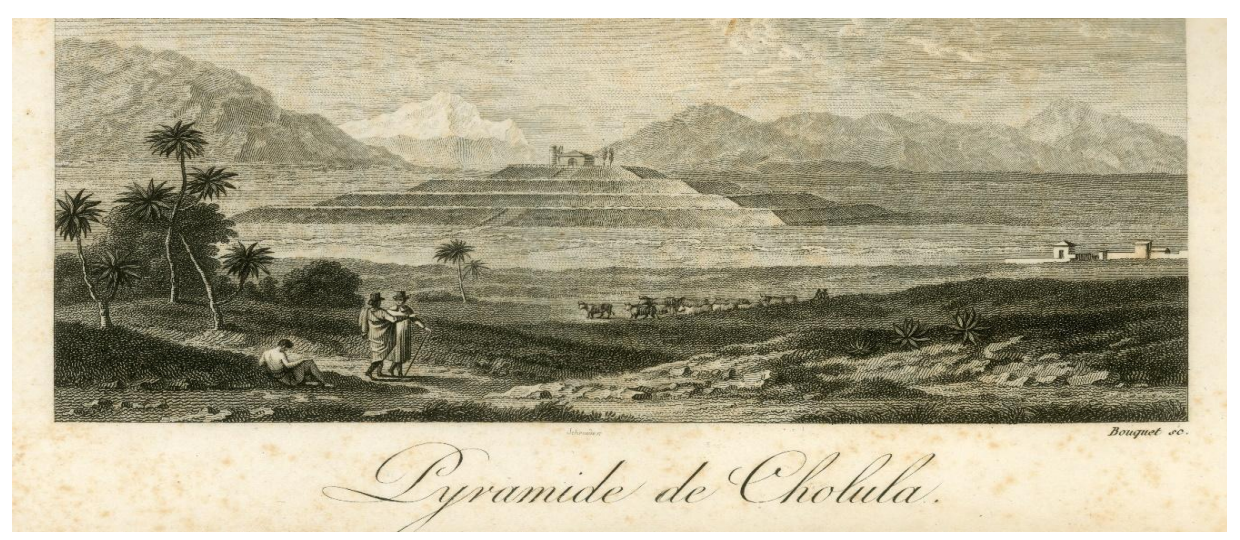

Figura 3. Ilustración de la Gran Pirámide de Cholula según las observaciones de Humboldt, representada en la publicación "Vues des Cordillères, et monumens des peuples indigènes de l'Amerique". Fuente: Rare Book Collection, Archives of the State Historical Society of Wisconsin (2009)

Por un lado, Cholula se ha caracterizado por sus raíces milenarias que han fusionado el sincretismo religioso y cultural con sus actividades agrícolas. Por otro lado, la región ha evolucionado de un centro religioso y rural a una concentración de universidades, habitacional y de servicios, por lo que su paisaje se ha modificado principalmente en términos de su estructura urbana.

El paisaje rural y social arriba descrito fue el que encontraron Humboldt y Bonpland cuando llegaron a México a principios del Siglo XIX. Al desembarcar en el puerto de Acapulco, el 11 de abril de 1803 hicieron su acto de presencia primero en la Ciudad de México visitando el Seminario de Minería y el Jardín Botánico, cuyo

\footnotetext{
${ }^{3}$ Sistema agrícola tradicional conformado por un policultivo entre maíz, frijol y calabaza.

${ }^{4}$ El nombre "Cholula" tiene su origen en la etimología "Chollollan" que significa "huida" o "carrera" "cholo-llan" o el lugar donde se corre. El jeroglífico representativo de la ciudad es un pie pisando un cerro. Por otro lado, también existe la interpretación "agua que cae en el lugar de la huida", relacionado con la llegada de grupos toltecas refugiados después del colapso de la ciudad de Tula. Paredes Lara (2004) cita a Walles (1971) que menciona que uno de los hijos del rey de Tula, llegando a lo que hoy es Cholula, buscó agua para apagar su sed y cuando encontró un manantial con agua cristalina, exclamó "at chollolan" por lo cual los pobladores llamaron el lugar con este mismo nombre.
} 
ambiente los impresionó por sus viajes y estudios previos en el subcontinente Sudamericano (García Farrero, 2015, p.322). Previo a su visita, Humboldt ya había conocido códices prehispánicos mesoamericanos y había adquirido en 1802, de los herederos de León y Gama, algunos de estos, entre ellos el Códice Boturini o Tira de Peregrinación que posteriormente entregó a la Biblioteca Nacional de Berlín donde se encuentra todavía hoy (Ashwell, 2004, p.50).

Entre conocer otras ciudades de Nueva España, Humboldt visitó también Cholula y su gran pirámide Tlachihualtépetl, ${ }^{5}$ que ya había conocido a través de los trabajos de los cronistas españoles del siglo XVI (Leysinger, 2004, p.304-305). Él describió este "cerro construido" prehispánico como "la mayor pirámide del mundo" (Minsch, 2008, p.42). Con base en su visita, hizo también un cálculo trigonométrico de los volcanes Popocatépetl e Iztaccíhuatl que separan el valle de Puebla del Valle de México y que forman un magnífico telón de fondo paisajístico para el Tlachihualtépetl, para estimar su altura, de Humboldt (1822), describe la gran pirámide como (figura 3):

La plataforma de la pirámide truncada de Cholula tiene 4,200 m2 de superficie. En medio de ella descuella una iglesia dedicada a Nuestra Señora de los Remedios que está rodeada de cipreses, en la cual todas las mañanas celebra la misa un eclesiástico de raza india, que vive habitualmente en la cima de este monumento. En esta plataforma tiene una vista deliciosa, pero que impone cierto respeto, pues se presenta a un tiempo mismo el volcán de La Puebla, el pico de Orizaba y la pequeña cordillera Matlatcueye que en otro ((tiempo separó el territorio de los Cholultecas, de los republicanos tlaxcaltecas. (p. 158)

El respeto al paisaje permitió a Humboldt relatar con detalle el sistema constructivo de la pirámide y su relación con otros teocalis ${ }^{6}$ ubicados en el altiplano, entre ellos Teotihuacán, y la vegetación endémica de la zona como las bellas plantaciones de maguey. Para 1793, Humboldt contabilizó que el distrito de Cholula tenía una población de 22,423 habitantes, distribuidos entre 42 pueblos y 45 haciendas.

En sus crónicas, Humboldt también relata que Cholula junto con Tlaxcala y Huejotzingo fueron de las pocas repúblicas de indios que resistieron a la dominación mexica o "imperio mexicano" (Humboldt, 1822, p.160. En esta visita a Puebla y a sus alrededores, presentó también críticas acerca del sistema de

\footnotetext{
${ }^{5}$ Como menciona Ashwell (2004), el desarrollo territorial de Cholula ha sido producto de un largo proceso civilizador que se desarrolló a partir de la intervención de diferentes pueblos, culturas y lenguas por lo que se ha encontrado vestigios de la presencia humana que data de por lo menos 20,000 años A.C. Entre el año 300 A.C. y el inicio de la era cristiana, Cholula se transformó rápidamente en una gran urbe. En esta época, fue construida la estructura piramidal más antigua del centro ceremonial cholulteca del periodo 200-100 A.C. (Ibídem), Tlachihualtepetl, "cerro construido" o la Gran Pirámide de Cholula dedicado al dios Quetzalcoatl. En la Historia Tolteca-Chichimeca, Tlachihualtepetl está representado como un cerro natural asociado con agua, árboles de tule y con flores (Barrio, 2006, p.818).

${ }^{6}$ Templos de los pueblos precolombinos de Mesoamérica.
} 
posesión de la tierra, encontrándolo contrario a la "prosperidad pública" (Minsch, 2008, pp. 40,42), reflejando su postura ante las políticas discriminatorias de Nueva España. También presentó críticas acerca de los efectos dañinos del monocultivo introducido por la colonia, así como acerca de las consecuencias destructivas de los sistemas de irrigación aplicados, así como de la deforestación que estaban deteriorando las condiciones naturales de los territorios conquistados por España (Sipmann, 2016, p.139).

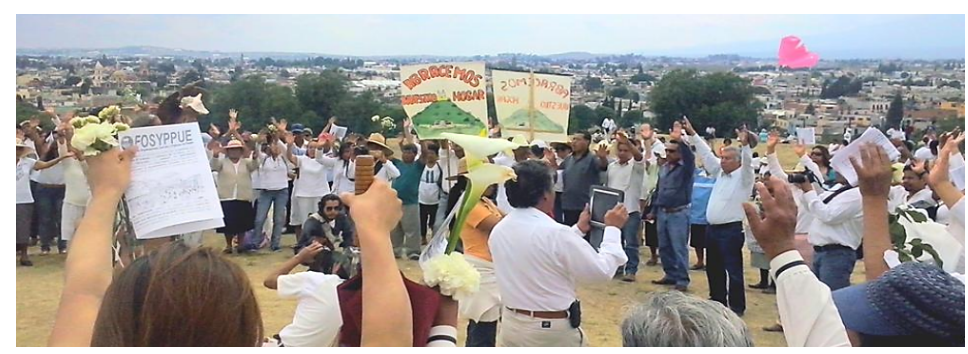

Figura 4. "Abracemos nuestro hogar" reunión comunitaria sobre la Gran Pirámide para protestar por las expropiaciones en torno a la zona arqueológica y en contra del proyecto "Parque de las 7 culturas o inter-municipal". Fuente: M. Schumacher (2015)

En las décadas posteriores a la visita de Humboldt, Bandelier, citado en Bonfil Batalla (1973) menciona que, a finales del siglo XIX, el trabajo de la tierra siguió siendo la ocupación más importante de los habitantes de Cholula mediante agricultura intensiva, de riego y de temporal con diversos ciclos a lo largo del año. A raíz de la Revolución Mexicana, el 2 de febrero de 1915, se promulgó un decreto en Cholula que detonó el desmembramiento de las haciendas y reparto agrario de tierras. Así empezó la conformación de ejidos ${ }^{7}$ y una recuperación del territorio cholulteca. Sin embargo, la tierra ahora en las manos de cada familia campesina nunca tuvo la extensión suficiente para permitir una subsistencia familiar a partir de la producción agrícola (Hernández-Flores \& Martínez-Corona, 2011).

A pesar de ello, la característica predominante de la agricultura local era ser minifundista (Bonfil Batalla, 1973). La vida rural en Cholula continuó su propio curso hasta el año 1988, cuando por el decreto de expropiación estatal, extensiones ejidales de cultivo de Cholula fueron asignadas como reserva territorial para el crecimiento de la vecina ciudad de Puebla. Estos anteriores ejidos fueron transformados en tierra urbana a partir del año 1993 (Schumacher, Durán-Díaz, Kurjenoja, Gutiérrez-Juárez, \& González-Rivas, 2019), por el Megaproyecto Angelópolis ${ }^{8}$ promovido por el gobierno federal y estatal. Este desarrollo fue posible por agresivas expropiaciones de tierras agrícolas de Cholula, detonando resistencias y juicios (Schumacher, 2016).

\footnotetext{
${ }^{7}$ El ejido se institucionalizó como un derecho agrario después de la Reforma Agraria en la década de 1920 en México. Eran las tierras comunales otorgadas a campesinos y agricultores.

${ }^{8}$ El nombre completo de la ciudad de Puebla, vecina de la zona de Cholula, es Puebla de los Ángeles, de allí el nombre "Angelópolis".
} 
Históricamente, la pérdida del territorio y las expropiaciones han sido el principal detonador de conflictos socio-espaciales. Incluso a partir de la denominación de San Andrés y San Pedro Cholula9 como "Pueblo Mágico"10 en 2012; el gobierno estatal operó su maquinaria expropiatoria para la expropiación de las tierras ubicadas alrededor de la pirámide.

Así nació el movimiento ciudadano para manifestarse no solamente para defender el patrimonio intangible y paisajístico de Cholula, sino también contra la construcción de proyectos turísticos que ponen en jaque la tenencia de la tierra, los cambios en los cauces de agua, gasoductos que ponen en peligro a los habitantes e inhabilitan terrenos de cultivo, y de la teatralización de la imagen urbana (Calleja, Martínez, \& Soto, 2014).

La manifestación social dentro de un entorno tan complejo como la Gran Pirámide y su santuario, tiene que ver además con el uso del espacio público como manifestación de la conciencia colectiva (ver figura 4), coincidiendo así con lo que mencionaba Humboldt que "el saber está, por consiguiente, siempre anclado en el espacio público. Sus conceptos universales pretenden crear una conciencia más compleja de la variabilidad de los mundos en un público lo más amplio posible" (Ette, 2019, p.15). Con ello, la visión totalitaria de Humboldt sobre el conocimiento y el cosmos, estuvo muy anclada no solo a través de sus viajes y mediciones por Cholula, México y América; tenían un profundo arraigo en el naturalismo alemán y el zeit-geist propio de la época que lo formó.

\section{Discusión teórica: concepción del paisaje figurativo humboldtiano}

El mundo en el que se educó Alexander von Humboldt del siglo XVIII tenía dos vertientes en la concepción de la naturaleza y el paisaje: por un lado, los académicos entendían y percibían a la naturaleza desde una visión materialista y mecanicista basado en los logros de la ciencia, "cuyo fin era permitir al hombre un mayor poder sobre la misma, facilitar su explotación posibilitando así su progreso, tan ilimitado como el avance propio del saber y de la ciencia" (Corberá Millán, 2014 , p.40). Por otro lado, la sociedad alemana reivindicaba el rol del hombre en relación con la naturaleza como uno de los estandartes del romanticismo alemán en todas sus facetas. Dicho ideal de unidad se entendía como "un todo absoluto e inabordable por la vía científica, sólo accesible por la intuición sensible, a través del arte, la belleza y la estética, y profesaban por ello, un auténtico panteísmo" (Corberá Millán, 2014, p.40).

\footnotetext{
${ }^{9}$ Cabe aclarar que la subdivisión territorial de Cholula no cambió en los tres siglos que duró el período colonial. La única transformación política drástica sucedió entre 1628 y 1640, cuando el barrio o Calpulli de San Andrés logró independizarse de San Pedro Cholula, como cabeza de doctrina, formando su curato propio. En 1714 San Andrés Cholula logró separarse definitivamente de San Pedro, constituyendo una nueva república de indios iniciando con ello una disputa territorial entre las dos poblaciones, principalmente debido a la diferencia étnica entre los grupos de indígenas asentados (Bonfill Batalla, 1973).

10 "Pueblos Mágicos" es un programa turístico creado en 2001 por la Secretaría de Turismo de México para distinguir a ciudades o poblados por su riqueza cultural y promoverlos como sitios turísticos.
} 
Para S. Schaffer (1990) esto quiere decir que áreas del conocimiento como la física "fuera tratada como un arte" y esto fue la base del pensamiento compartido por los llamados "investigadores de la naturaleza", Natureforscher como Novalis, Schilling, Schiller y Goethe (Pimentel, 2004). Dicho grupo de pensadores construían una filosofía de la naturaleza basada no solo en el estudio científico y empírico, sino también plasmada a través del arte, que era el único medio capaz de "captar la naturaleza en su totalidad (Corberá Millán, 2014, p.43). Especialmente Goethe afirmaba que "si el hombre se expresaba con palabras, la naturaleza lo hace con imágenes, es decir, con paisajes" (Corberá Millán, 2014, p.43). Precisamente, dicho lenguaje era la base de Humboldt para el estudio del paisaje, donde el ojo tenía que ser entrenado para ser "capaz de reconocer con claridad los objetos de la naturaleza, debe asimismo estar preparado para captar en ciertos momentos la totalidad de la naturaleza más allá de los objetos concretos" (Corberá Millán, 2014, p.44)

La visión de Goethe está muy presente en la epistemología germana de la época donde el pensar en conjunto [Zusammendenken] solo puede conformarse mediante la correlación de diferentes áreas, espacios y culturas. Por esta razón Humboldt tuvo que complementar su viaje a América con una expedición a Asia, puesto que solo de esta manera se hacía posible un pensar dentro de lo otro [Ineinanderdenken] productivo acerca distintos espacios, tiempos y culturas. (Ette, 2019, p.18)

En la comprensión del modelo humboldtiano podemos referir todavía a Heidegger y Bollnow y su estudio del espacio a través de la vivencia y experiencia humana. Para Heidegger, el ser humano existe en el espacio, porque este le proporciona un lugar, un "espacio intencional" (Heidegger, 2003, p.82) y para Bollnow, el ser humano habita lo que él llama "espacio vital", en tres posibles estadios (Bollnow, 1969, p.256-270): el del propio cuerpo, el de la propia casa y el del espacio realmente habitado (García Farrero, 2015, p.325). En el contexto de la interconexión entre el medioambiente y el ser humano que lo ocupa, el concepto de "habitar" de Heidegger declara que habitar es el modo en que los mortales ocupan la Tierra (Heidegger, 1997, p.97). En este mismo sentido de explorar el mundo a través de la experiencia y la vivencia, en su metodología Humboldt enfatizaba la importancia del proceso de sorpresa, curiosidad, observación, interrogación, hipótesis, experimentación, comparación, debate y conclusión (Cuesta Domingo, 2008, p.61).

Como revela lo anteriormente descrito, Humboldt difería del entendimiento científico del momento acerca de la vegetación. Mientras para la visión científica de la época, el entorno natural fue considerado como un ente homogéneo, Humboldt lo conceptualizó como heterogéneo, declarando que hay regiones naturales con sus propias particularidades y no un universo natural uniforme (Moreno Kegel, 2019). En este contexto, él fundamentó lo que posteriormente serían las bases de la ecología moderna, de la distribución de plantas, de pisos térmicos y ecológicos, así como la valoración del desarrollo cultural en función de las condiciones ambientales, de la geografía humana y la relación entre el ser humano y su medio (Cuesta Domingo, 2008, pp. 61-62). En el sentido del presente artículo, y refiriendo 
a las palabras del propio Humboldt (von Humboldt, Alexander; Bompland, 1826, p.3), se enfatiza la importancia de la idea de la "relacionalidad" en el universo:

[...] la naturaleza, considerada por medio de la razón, es decir sometida en su conjunto al trabajo del pensamiento, es la unidad en la diversidad de los fenómenos, la armonía entre las cosas creadas, que difieren por su forma, por su propia constitución, por las fuerzas que las ha animado, es el Todo animado por un soplo de vida. (Minsch, 2008, p. 282)

Además de acentuar la importancia de la complejidad y diversidad de los datos recabados de Humboldt, en el sentido de su visión transdisciplinaria entre la ciencia y las artes:

La materia que trato es tan vasta y tan variada, que temo abordar el asunto de una manera de superficialidad enciclopédica (...) la historia natural filosófica de la Naturaleza, se eleva sobre las necesidades de una mera descripción de la Naturaleza. No consta de una acumulación estéril de hechos aislados. (Humboldt, 1849, II, p. 289)

La idea de la ambigüedad materialista e idealista del paisaje estaba presente en los viajes de Humboldt y Bonpland en que con todo tipo de instrumentos de medición y recolección de muestras lograron describir la grandeza del mundo natural y paisajístico de Latinoamérica, que para entonces era objeto de desconocimiento y fantasía para el mundo europeo. Con Humboldt, la representación del paisaje cumplía no solo la función estética, sino que se encontraba a disposición de la ciencia misma como un elemento de transmisión del conocimiento (Garrido, Rebok, \& Puig-Samper, 2016).

Humboldt era consciente que, para dar mayor difusión a su trabajo, el poder de la imagen era básico, por lo que recurre a la ilustración como una herramienta complementaria de mediciones y observaciones. Para Corberá Millán la colaboración entre ciencia y arte presente en el trabajo de Humboldt describen que:

La literatura y pintura contribuyen a la compresión de la ciencia e incitan a la exploración y al trabajo científico, la ciencia, por su parte, podía igualmente contribuir a la mejora de la expresión artística, mostrándole la formas desconocidas y exóticas de la vegetación y su distribución altitudinal (Corberá Millán, 2014 p. 56)

En resumen, la cosmovisión naturalista de Humboldt se centraba en los siguientes postulados: una interrelación hombre-naturaleza (Cuesta Domingo, 2008); la causalidad a interrelación de los fenómenos naturales como manifestación física de una unidad (Corberá Millán, 2014); pensar en conjunto [Zusammendenken] y pensar dentro de lo otro [Ineinanderdenken] (Ette, 2019); el análisis científico como un todo (Cuesta Domingo, 2008); (Garrido et al., 2016a); la ambigüedad entre armonía y orden del cosmos (Corberá Millán, 2014); la aceptación de la influencia positivista de la naturaleza en la moralidad e inteligencia de los pueblos (Corberá Millán, 2014); y el sentimiento holístico del paisaje a través del detalle (Garrido et al., 2016). 


\section{La pintura de la naturaleza}

En 1802, Alexander von Humboldt y Bonpland llegaron hasta el volcán Chimborazo en los Andes, que con sus 6268 metros era la montaña más alta del mundo conocido en ese entonces. En la subida a la cima, Humboldt registró las especies vegetales que había a cada altura mientras escalaba (Criado, 2015). Sus impresiones sobre el microcosmos entorno al volcán fueron publicadas en francés de Geographie des plantes équinoxiales o "Ensayo sobre la geografía de las plantas" en 1807.

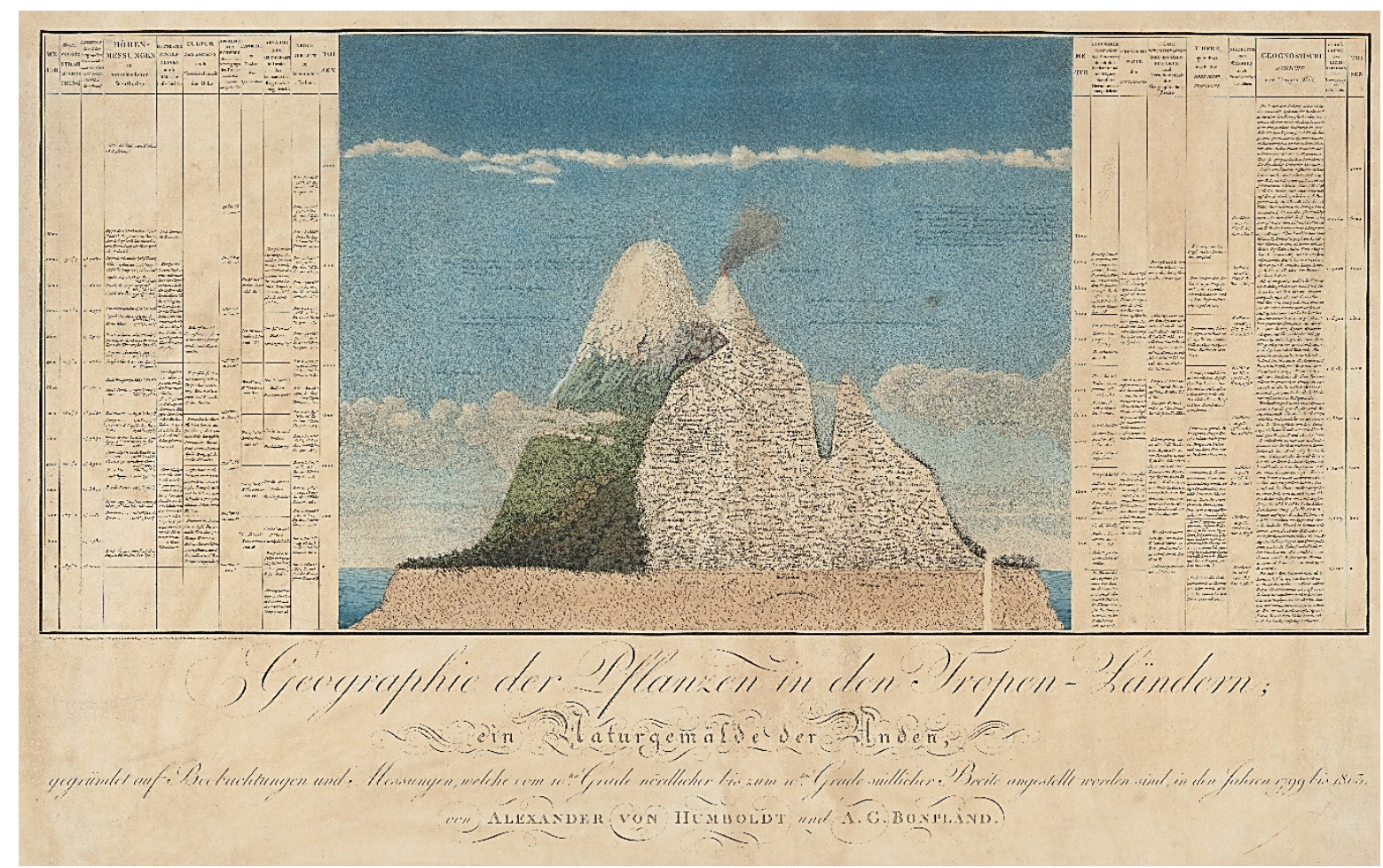

Figura 5. Humboldt, Bonpland (1807) Ideen zu einer Geographie der Pflanzen nebst einem Naturgemälde der Tropenländer. Fuente: Zentralbibliothek Zürich Public, licencia de dominio público

En este documento Humboldt intentó expresar la historia biológica en su relación con el paisaje en un extenso mapa donde se representó una "Tableau Physique" o cuadro físico de las regiones equinocciales, el reconocido Naturgemälde representado en este documento en la Figura 5. El objetivo de este trabajo era representar cómo cambiaba la vegetación de los volcanes Chimborazo y Atisana, conforme aumentaba la altitud.

Dicha representación describe la montaña a través de una sección transversal en que diferentes zonas vegetales, detalles de altitud, temperaturas, etc. aparecen en una visualización de condiciones medioambientales sin precedente (Sipmann, 2016, p.140). 
Para muchos este Tableau physique es especial como obra maestra de infografía mucho antes que esta disciplina haya nacido formalmente. En él, en gran detalle, se menciona los datos acerca de la temperatura, humedad, presión atmosférica, y del borde inferior del glaciar, así como especies de plantas que había a cada altura y las dependencias entre el entorno natural y las culturas locales en forma de observación de, por ejemplo, hasta dónde llegaban los cultivos de patatas y donde pastaban las llamas. Esta descripción figurativa ha sido, para la ciencia contemporánea, una ventana al pasado, pero también una herramienta para estudios comparativos para observar los cambios en el medio ambiente de los Andes (Criado, 2015).

Cabe aclarar las diferencias entre los usos del francés y alemán para definir "la tabla física" de los Andes. En la versión en francés, Humboldt utiliza Tableau Phisyque des Andes et pays voisins y en alemán Geographie der Pflanzen in den Tropen-Ländern - Naturgemälde der Anden (figura 5), siendo popularizada la versión en francés. Sin embargo, este trabajo prefiere utilizar la versión alemana ya que la traducción literal de "pintura de la naturaleza" es más acertada que la "tabla física", porque la versión en alemán "entraña una sensación de unidad o integridad [...] un microcosmos en una página" (Wulf, 2016, p.115).

La representación pictórica elaborada por Humboldt, además de documento científico, es una gran obra de arte. Es un mapa bello de colores, símbolos y de pasigrafía humboldtiana o lenguaje de signos comprensible a todos que revela datos geológicos y cartográficos de una manera universalmente legible. La representación, para hacerla más viva y legible, es ilustrada por elementos complementarios tales como flechas e imágenes diversos como fumarolas, y por técnicas de dibujo como sombreados y rayados (Cuesta Domingo, 2008, p. 50). También registra cuestiones de la población, de las actividades productivas, notas históricas y etnográficas (p. 56). Así como en Chimborazo, Humboldt realizó una gran cantidad de dibujos y bocetos que describen motivos paisajísticos, botánicos, zoológicos, topográficos y geológicos que fueron base para las 1425 láminas realizadas por unos 50 artistas para ilustrar su obra magna Viaje a las regiones equinocciales del Nuevo Continente (París, 1805-1834) y borradores para mapas y perfiles biogeográficos (p. 281). A través de su trabajo, Humboldt manifestó su idea de la naturaleza como un cosmos constituido a través de interrelaciones y su capacidad artística le permitió captar la fisonomía del paisaje en su totalidad y (p. 282) transmitir los resultados de sus estudios que hoy día podríamos llamar como observaciones socio-ecológicas.

Además de resumir su visión holística y naturalista del mundo (Antón, 2019), Humboldt también estableció que en el paisaje figurativo se podían establecer "un conjunto de fuerzas interrelacionadas y éstas componen un todo que nos brinda esa impresión total, pero que al mismo tiempo también puede ser diseccionado y valorado por cada detalle individual" (Garrido et al., 2016, p.375).

Más allá de cualquier mapa de la época, lo interesante de la presentación gráfica y el ensayo figurativo es el corte geográfico (Kraft, 2017). La ascensión a la cumbre del Chimborazo fue simbólica, como ya se mencionó previamente, se consideraba la montaña más alta del mundo y que para frustración de Humboldt, no pudo subir hasta la cúspide. Como describe A. Wulf: 
[...] las montañas hechizaban a Humboldt. No solo las exigencias físicas y las perspectivas de nuevos conocimientos. Había también algo más trascendental. Cada vez que estaba en una cumbre o un cerro, se sentía tan conmovido por el paisaje que dejaba volar aún más su imaginación". Una imaginación, decía, que aliviaba las profundas heridas que a veces causaba la pura razón (Wulf, 2016, p.109)

Dicho simbolismo también tiene mucho que ver con la ya descrita asociación del pueblo alemán con un sentimiento de sincretismo y exaltación a la madre naturaleza. Por ende, la montaña se convierte en la imagen "sublime" de comunión entre narrativa y ciencia (Pimentel, 2004, p.19).

Tanto en la lámina comparativa entre volcanes (Figura 1) como en el Naturgemälde, Humboldt definiría que, en toda representación pictórica de una región, era esencial representar "las asociaciones vegetales en función del clima" (ibídem, p.369). Además, Garrido et al. (p.377) citan a Pimentel, cuando él expresa como Humboldt esperaba ilustrar todos los fenómenos naturales en una sola unidad-imagen compuesta desde el plano geográfico a la escala humana, fomentado la creación de la geobotánica o fitogeografía (Pimentel, 2004). Estas expresiones biofísicas del territorio también permitieron a Humboldt y Bonpland estudiar los cambios en los usos de suelo y de vegetación del trópico a través de la transformación de las actividades agrícolas y deforestación por obra humana (Ponette-González et al., 2013).

Cabe mencionar que Corberá Millán (2014) expresa algunas limitaciones que presentó Humboldt en su ilustración paisajística. Señala que el ensayo es una representación reduccionista del paisaje donde la capa vegetal predomina por encima de otros como instrumento de medición y comparación de causas y efectos.

\begin{tabular}{clll}
\cline { 2 - 3 } & $\begin{array}{l}\text { PAUTAS DE } \\
\text { ELABORACIÓN }\end{array}$ & PLANOS DE ANÁLISIS & $\begin{array}{l}\text { CONCEPCIÓN DE LA } \\
\text { NATURALEZA }\end{array}$ \\
\cline { 2 - 4 } & $\begin{array}{l}\text { Fisionomía de las } \\
\text { plantas en conexión } \\
\text { con su hábitat }\end{array}$ & $\begin{array}{l}\text { PLANO AISLADO (CUADRO } \\
\text { INDIVIDUAL) } \\
\text { Estudio individual de la } \\
\text { FIGURAISIS }\end{array}$ & $\begin{array}{l}\text { Ambigüedad orden / } \\
\text { armonía }\end{array}$ \\
\cline { 2 - 4 } & $\begin{array}{l}\text { Asociación vegetal } \\
\text { en función del clima }\end{array}$ & $\begin{array}{l}\text { PLANO MEDIO (CUADRO } \\
\text { PRECISO) }\end{array}$ & $\begin{array}{l}\text { Fenómenos naturales } \\
\text { como manifestación } \\
\text { física de la naturaleza } \\
\text { como unidad }\end{array}$ \\
& Asociación vegetal y animal \\
& & $\begin{array}{l}\text { Modificaciones hechas por } \\
\text { los humanos }\end{array}$ & \\
& & Topografía, geografía, altitud & \\
& &
\end{tabular}




$\begin{array}{lll}\begin{array}{l}\text { Representación } \\ \text { topográfica exacta } \\ \text { de la naturaleza }\end{array} & \begin{array}{l}\text { PLANO DISTANTE } \\ \text { (CUADRO-PAISAJE) }\end{array} & \begin{array}{l}\text { Influencia positivista de } \\ \text { la naturaleza }\end{array} \\ & \begin{array}{l}\text { Representación general del } \\ \text { contexto }\end{array} & \begin{array}{l}\text { Impresión total del } \\ \text { paisaje a través del } \\ \text { detalle }\end{array} \\ \end{array}$

Cuadro 1. Elementos de elaboración de un análisis figurativo Humboldtiano. Fuente: adaptado de Garrido et al. (2016) y Corberá Millán (2014).

Según el Cuadro 1, Garrido et al. (2016) describen las características principales del análisis figurativo del paisaje que creó Humboldt. Con base en su concepción de la naturaleza, los autores establecen tres planos de análisis de los cuadros humboldtianos, según la escala de trabajo. En primer lugar, el plano individual es donde se hace el estudio aislado de un elemento natural como una planta, como base para leer su fisonomía y relación con el contexto. En segundo lugar, está el cuadro medio o preciso donde se establece la asociación vegetal y natural con las intervenciones humanas, así como la medición más exacta de las características geográficas y físicas del lugar. Por último, el plano distante o cuadro-paisaje, es donde la estética da una representación exacta y general de la naturaleza y que corresponde a la influencia positivista que el medio natural ha dado a la civilización. Con todo lo anterior, los autores reflexionan sobre el trabajo del naturalista porque:

Humboldt propone el estudio de la Naturaleza de acuerdo al orden figurativo de un cuadro y escoge la complejidad paisajística de la montaña como el lugar ideal de representación, ya que yuxtapone la voluntad de conocimiento con un sentimiento ilimitado de emoción. Considera además que la actividad artística es un buen medio para comprender la diferenciación y la diversidad de la naturaleza. Se pasaría del cuadro virtual narrativo al verdadero cuadro artístico, aunque en ambos habría que conseguir provocar la misma emoción experimentada por el viajero ante la observación de la naturaleza... (Garrido et al., 2016, p.373)

En palabras de Humboldt (1826), el autor describe que en su ensayo sobre geografía de las plantas:

He tratado reunir en un solo plan el conjunto de fenómenos físicos que presenta la parte del nuevo continente, comprendida en la zona tórrida, desde el nivel del mar del Sur hasta la cumbre más elevada montaña de los Andes; a saber; la vegetación, los animales, las relaciones geológicas, la cultura del sol, la temperatura del aire, los límites de las nieves perpetuas, la constitución química de la atmósfera, su tensión eléctrica, su presión barométrica, la disminución de la gravitación, la intensidad del color azulado celeste, la debilidad de la luz durante su paso por las camas sobrepuestas al aire, las refracciones horizontales, y el calor del agua hirviendo a diferentes alturas. Catorce escalas dispuestas al lado de un perfil de los Andes indican las modificaciones que sufren estos fenómenos por la influencia de la elevación del suelo por cima del nivel del Océano. 
Schumacher, M y Kurjenoja, A. (2021) Tekoporá vol. 3, n¹ (139-167) DOI 10.36225/tekoporá.v3i1.114

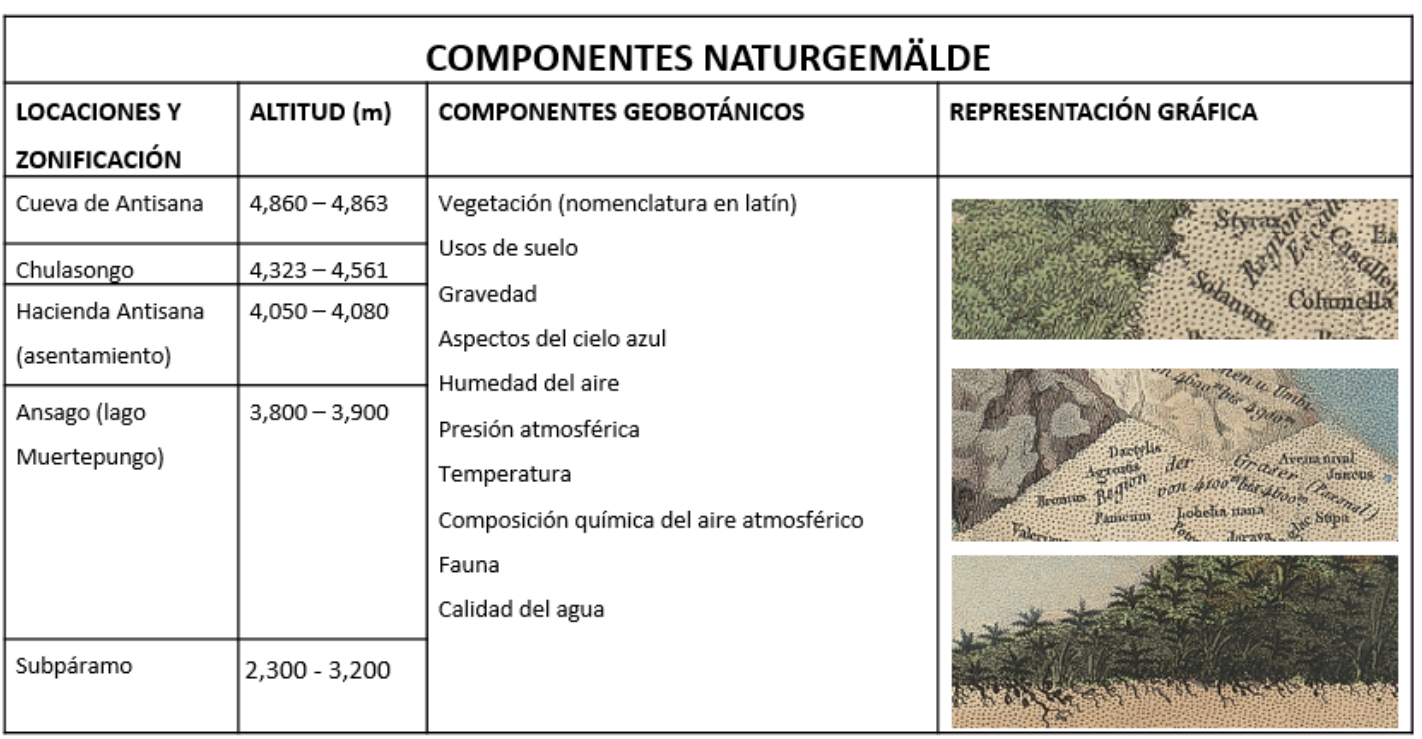

Cuadro 2. Componentes del Naturgemälde. Adaptado de Moret et al. (2019) y Humboldt (1826)

Cada grupo de vegetales está colocado a la altura que la naturaleza le ha señalado, y puede seguirse la prodigiosa variedad de sus formas... Estas regiones forman las divisiones naturales del imperio vegetal; y así como las nieves perpetuas se encuentran en todo clima a una altura determinada, así las especies febrífugas de quina tienen también los límites fijos que he indicado en el mapa botánico que acompaña a este ensayo sobre geografía de las plantas. (xxxij)

La pintura de la naturaleza sobre los volcanes ecuatorianos permite que se puedan analizar en una sola imagen, una "serie de elementos dispersos que no pueden ser apreciados en un lugar concreto o físico" (Pimentel, 2004, p.12). Corberá Millán enfatiza que la ilustración "descubre la importancia de la fisonomía de la naturaleza para la singularización de los espacios geográficos, para su clasificación y comparación". Para el autor, esa es la mayor aportación de Humboldt a los estudios de geografía del paisaje, aunque critica a su vez, que falta rigurosidad científica y se pierde de cierta manera en lo estético (p.58). Por un lado, está claro para el autor, que Humboldt lo hace a propósito, el Naturgemälde se vuelve un instrumento iconográfico de estudio como guía comparativo de sitios particulares, pero no para usarse como un instrumento riguroso de análisis geográfico (p.59). Por otro lado, la revisión realizada por Moret, Muriel, Jaramillo \& Dangles (2019) del Naturgemälde donde se actualizan los datos obtenidos por Humboldt y Bonpland, confirman que la primera edición de la tabla física contiene errores de ubicación de vegetación y altitudes, pero versiones posteriores del Naturgemälde fueron actualizándose hasta 1825. Los investigadores afirman que los traspiés de altitud y locación de Humboldt no cambian el hecho que su concepción sobre un anillo de vegetación fue revolucionaria y estos datos siguen vigentes para su análisis e interpretación (los componentes de estudio se describen en el Cuadro 2). Además, dicho estudio de actualización menciona que el Naturgemälde no debe de ser visto como una versión exacta de las teorías de Humboldt sobre representación 
de la naturaleza, sino más bien como un marco dinámico para la geobotánica (ibídem).

En la ilustración complementaria de Humboldt y Bonpland donde retoman el análisis de volcanes, es el "Distributione geographica plantarum secundum coeli temperiem et altitudinem montium, prolegomena" (Figura 1), donde aparece el volcán Popocatépetl como parte de las mediciones en geobotánica que realizaron los científicos en su paso por el virreinato de la Nueva España, hoy el territorio mexicano.

\section{Sistemas Socio-Ecológicos de paisaje (SES) y el Natürgemälde}

En la obra de Alexander von Humboldt, se unen la Ilustración renacentista y el Romanticismo del siglo XVIII que le permitieron forjar la nueva concepción de la naturaleza como un sistema integrado y considerar el ser humano y sus actividades como parte de él, identificando muy tempranamente vulnerabilidades causadas por la actividad humana (Sipmann, 2016, p. 138). De la Ilustración adoptó el registro científico preciso y estricto de los diferentes fenómenos que observó y del Romanticismo, la emoción y el sentimiento casi poético, de cómo la naturaleza tenía que ser experimentada a través de sentimientos (Rawding, 2017). Es de subrayar que, en su contexto histórico del colonialismo, Humboldt resaltaba la importancia del conocimiento local cuando los pueblos originarios fueron vistos como "salvajes" que tenían que ser "civilizados" (Castree, 2013, p.195-208). Su trabajo fue también revolucionario y un antecedente importante para el movimiento ecológico contemporáneo por su visión acerca de la relacionalidad entre contextos ambientales, culturales y económicos y su insistencia en la íntima relación entre lo "físico" y lo "humano" en una vista integrada acerca del medioambiente. Para la ecología de hoy, la profunda compresión de Humboldt acerca de los seres humanos como componentes claves dentro de ecosistemas es de enorme relevancia (Rawding, 2017).

En el discurso de Humboldt, "naturaleza" es mucho más que "natural"; implica la comprensión de lo social, económico y político. En él, todas las especies incluyendo la especie humana, modifican sus entornos para facilitar su propia reproducción. Así, los entornos están en procesos de transformación continuos. De la misma forma, la cultura y el modo de vida transforman la percepción humana acerca del entorno que nos rodea. Como Castree $(2005$, p.2) menciona, el surgimiento del concepto de la biodiversidad ha detonado los enfoques en la variedad dentro de los ecosistemas y en las maneras sorprendentes que estas pueden surgir y desarrollarse, subrayando la importancia de la comprensión de las relaciones de dependencia entre los diferentes factores medioambientales, como ya se vislumbran en el trabajo de Humboldt. Así, en la obra culminación de su vida científica, Cosmos (1845), Humboldt promovió la comprensión de la "maravillosa red de vida orgánica" que generó los cimientos para la ecología como una rama de ciencia para estudiar los sistemas y dependencias medioambientales complejos (Rawding, 2017).

En el marco de la relacionalidad humboldtiana y dependencias medioambientales, podemos destacar el surgimiento del concepto introducido por 
Bürgi \& Gimmi (2007), del Sistema Socio-ecológico del paisaje (SES). Este concepto enfatiza la importancia de la preservación del patrimonio cultural de los paisajes y del conocimiento tradicional de su habitación, ya que la pérdida del conocimiento medioambiental tradicional representa un deterioro en el patrimonio cultural del mundo.
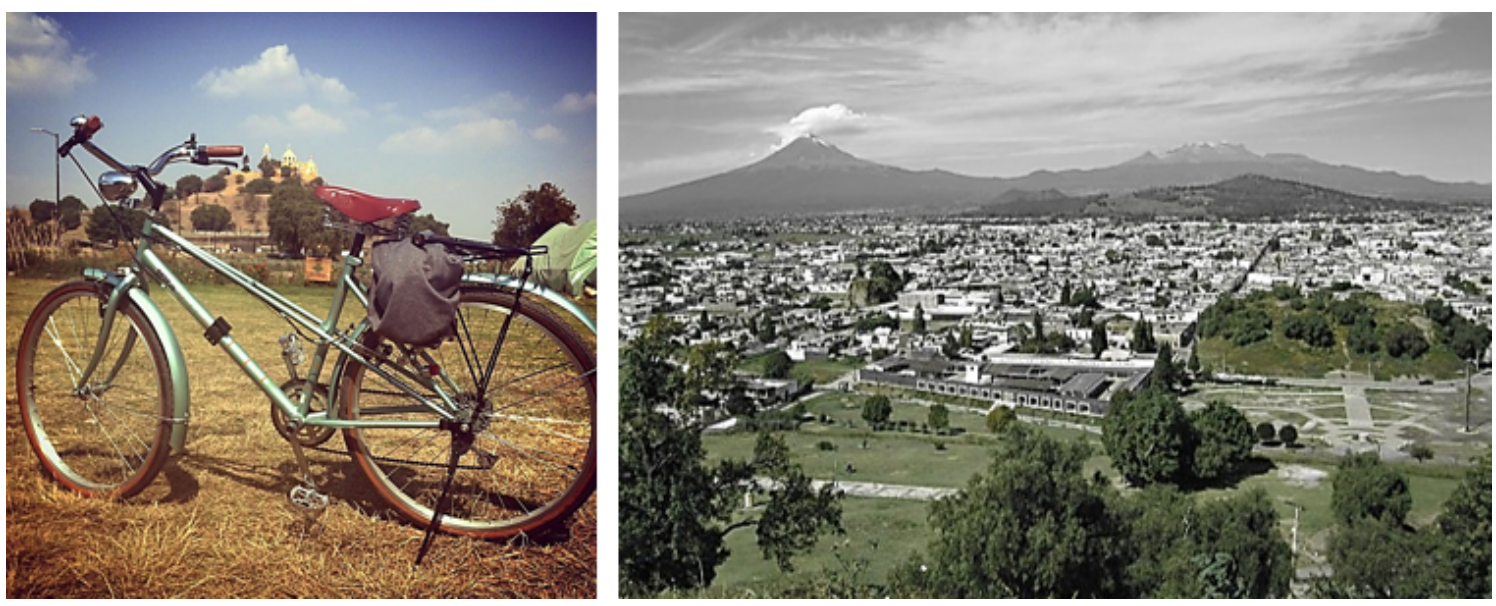

Figura 6. La Gran Pirámide de Cholula o Tlachihualtépetl y la vista de los volcanes Popocatépetl e Iztaccíhuatl desde el Santuario de Los Remedios; éste fue el paisaje que tanto impresionó a Humboldt. Fuente: M. Schumacher $(2016,2009)$

Por lo tanto, los estudios de cambios en los paisajes requieren información detallada de las actividades humanas en relación con el contexto. Así, es esencial comprender las trayectorias históricas de los procesos en el paisaje a través del análisis histórico. Esto proporciona información vital sobre las actividades humanas y sus patrones, y sobre los procesos históricos del paisaje para poder desarrollar estrategias y técnicas sostenibles del manejo del paisaje y de la tierra fundamentadas en la evaluación de la intensidad de las actividades humanas que los impactan y transforman.

\section{Resultados y discusión: apreciación paisajística-analítica del Natürgemälde en Cholula}

La definición del paisaje cholulteca en los ojos de Humboldt, redibuja la yuxtaposición de capas socio-territoriales y culturales que han evolucionado a lo largo de los siglos. Como se mencionó en párrafos anteriores, el Altépetl cholulteca tiene plasmada en su territorio la transformación social de sus límites y construcciones, así como el sincretismo cultural-religioso representado por el hito paisajístico por excelencia: la Gran Pirámide Tlachihualtépetl, el "cerro construido" que en conjunto con la presencia de los volcanes Popocatépetl e Iztaccíhuatl, se impregna en la memoria colectiva de sus habitantes (Figura 6). La defensa del hito cholulteca no ha estado exento de conflicto y polémica. Bajo la imagen de la pirámide y sus campos de cultivo, la población originaria y flotante se identifica y hace suyo el paisaje. A pesar de las expropiaciones, cambios en los usos de suelo y densidades urbanas, Cholula sigue siendo un espacio ru-urbano sagrado donde todo el que lo habita, lo reconoce, lo asume y defiende (Figura 7). 
Es por ello que, compartiendo la mirada humboldtiana que "engloba al ser humano en su totalidad, en el sentido del término griego bios, particularmente con su tejido y diversidad cultural, sus influencias y movimientos [...]" (Ette, 2019, p.29), el paisaje de Cholula sigue imponiendo respeto.
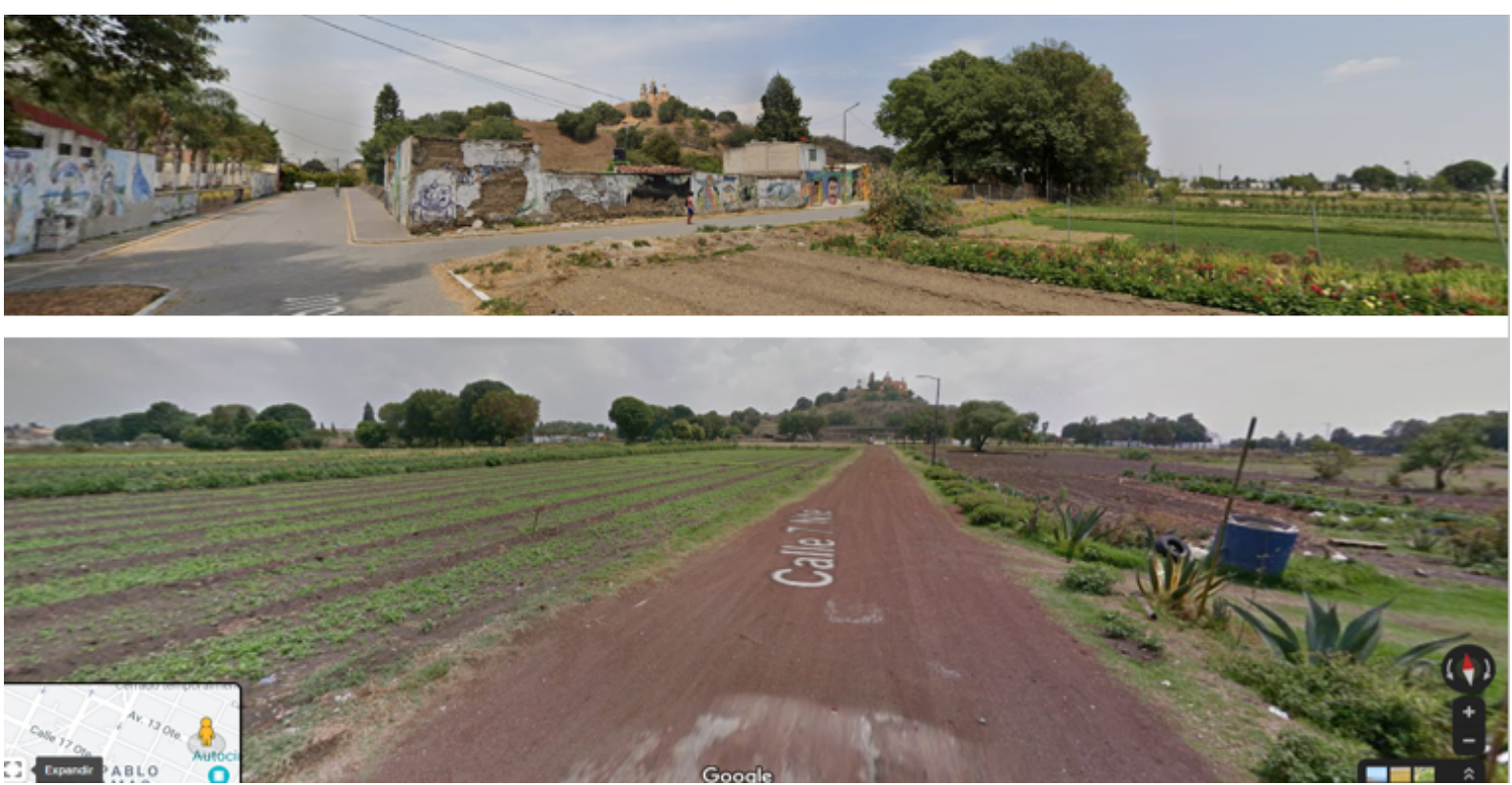

Figura 7. Parcelas agrícolas que se encuentran dentro del perímetro arqueológico y agrícola de Cholula. Al fondo la Gran Pirámide con el Santuario de los Remedios. Dependiendo del calendario agrícola, estas parcelas se llenan de hortalizas o flores. Estos terrenos han sido espacios de disputa por expropiaciones y abandono de las actividades rurales. Fuente: Google Street View (2017)

Según su evolución socio-territorial, el tejido yuxtapuesto que merece la pena destacar y que se propone como adaptación del Naturgemälde consiste del tejido ru-urbano (nuevas ruralidades), tejido urbano (urbanización), tejido social (barrios y mayordomías), tejido paisajístico (hitos) y tejido natural (reservas protegidas) con los siguientes componentes presentados en el Cuadro 3. En dicho cuadro se presentan, además la propuesta de capas de análisis, los planos y asociaciones en torno a su función basados en Garrido et al. (2016). 


\begin{tabular}{|c|c|c|c|c|}
\hline & TEJIDO & CAPAS & $\begin{array}{l}\text { PLANOS DE } \\
\text { ANÁLISIS }\end{array}$ & $\begin{array}{l}\text { ASOCIACIÓN-FU } \\
\text { NCIÓN }\end{array}$ \\
\hline \multirow{5}{*}{$\begin{array}{l}\text { PAISAJE } \\
\text { fIGURATIVO } \\
\text { DE } \\
\text { CHOULA }\end{array}$} & $R U-U R B A N O$ & $\begin{array}{l}\text {-Uso de suelo } \\
\text { agrícola } \\
\text {-Tierra vacante } \\
\text {-Agricultura } \\
\text { urbana }\end{array}$ & $\begin{array}{l}\text { INDIVIDUAL- } \\
\text { MEDIO-DISTANTE }\end{array}$ & $\begin{array}{l}\text { Población } \leftrightarrow \\
\text { suelo }\end{array}$ \\
\hline & URBANO & $\begin{array}{l}\text {-Uso de suelo } \\
\text { urbano } \\
\text {-Fraccionamie } \\
\text { ntos } \\
\text {-Infraestructur } \\
\text { a urbana } \\
\text {-Densidad }\end{array}$ & MEDIO-DISTANTE & $\begin{array}{l}\text { Población } \leftrightarrow \\
\text { aspectos } \\
\text { económicos y } \\
\text { sociales }\end{array}$ \\
\hline & SOCIAL & $\begin{array}{l}\text {-Barrios } \\
\text { urbanos } \\
\text {-Barrios } \\
\text { rurales }\end{array}$ & MEDIO & $\begin{array}{l}\text { Población } \leftrightarrow \\
\text { aspectos } \\
\text { socioculturales }\end{array}$ \\
\hline & PAISAJÍSTICO & $\begin{array}{l}\text {-Hitos } \\
\text { naturales } \\
\text {-Hitos } \\
\text { arquitectónico } \\
\text { s } \\
\text {-Hitos } \\
\text { intangibles }\end{array}$ & MEDIO-DISTANTE & $\begin{array}{l}\text { Población } \leftrightarrow \\
\text { biocultura } \leftrightarrow \\
\text { asentamiento }\end{array}$ \\
\hline & $\begin{array}{l}\text { GEO-BOTÁNI } \\
\text { CO }\end{array}$ & $\begin{array}{l}\text {-Reservas } \\
\text { naturales } \\
\text { protegidas } \\
\text {-Vegetación } \\
\text {-Temperatura } \\
\text { y presión } \\
\text { atmosférica } \\
\text {-Topografía } \\
\text {-Calidad del } \\
\text { aire } \\
\text {-Calidad del } \\
\text { agua }\end{array}$ & $\begin{array}{l}\text { INDIVIDUAL- } \\
\text { MEDIO-DISTANTE }\end{array}$ & $\begin{array}{l}\text { Naturaleza } \leftrightarrow \\
\text { Paisaje }\end{array}$ \\
\hline
\end{tabular}

Cuadro 3. Propuesta de análisis figurativo del paisaje humboldtiano para Cholula. Fuente: M. Schumacher (2020) adaptado de Garrido et al. (2016), Humboldt (1826).

Para un mayor análisis ru-urbano, la consideración de los usos de suelo existentes en las cartas urbanas (de zonificación) de cada municipio son herramientas útiles, pero que no siempre coinciden con el uso actual o con la velocidad de cambios que produce la población. Evidentemente el componente geo-botánico rescata el espíritu humboldtiano para un proceso de análisis geográfico mucho más complejo. Por otro lado, los cambios en la composición de la población cholulteca y su territorio, requieren complementar el lenguaje urbano de usos de suelo, así como patrimonio tangible e intangible. 
Como complemento, en el Cuadro 4 se establecen los tejidos de análisis visual para el territorio de Cholula. Se puede apreciar la relación de los hitos tangibles e intangibles en relación con los usos de suelo y sus densidades.

Cabe señalar que la capa social-urbana es la que delimita las costumbres y cambios de este continuo Altépetl que no ha dejado de ser ocupado desde su fundación.

Para ejemplificar los diferentes niveles de plano que se proponen, en la Figura 7 se muestra un plano medio-distante donde la Gran Pirámide o Tlachihualtépetl da la unidad al entorno inmediato (arquitectura-agricultura urbana). En este plano, el uso de suelo es predominantemente urbano, pero con un componente agrícola en los últimos cultivos supervivientes de flores. La densidad es media-baja y abundan los usos de suelo urbanos mixtos y de servicios. Cabe resaltar que este plano es compartido por los municipios de San Pedro Cholula y San Andrés Cholula, regidos por la mayordomía central del Santuario de los Remedios que ahora ocupa la cima del Tlachihualtépetl.

Con vista al poniente, el plano medio se convierte en plano distante (Figura 9, primera imagen) en que se plasma la imagen colectiva del paisaje de Cholula con los volcanes Popocatépetl e Iztaccíhuatl dominando el valle poblano y con elementos secundarios como los cerros Zapotecas, Tecajete y Teotón a sus pies. Sin embargo, al alejarse del plano total distante, se puede volver a una escala individual para el análisis de los cultivos supervivientes donde, dependiendo de la temporada del año, se siembra cempasúchil, ${ }^{11}$ flor nube, girasoles $\mathrm{u}$ hortalizas.Cuadro 4. Propuesta de visualización del tejido territorial en Cholula. Fuente: M. Schumacher (2020) adaptado de Google Earth INEGI (2020).

\footnotetext{
${ }^{11}$ Del Náhuatl “cempoaxóchitl”, nombre con el que se denomina a la flor de muerto.
} 


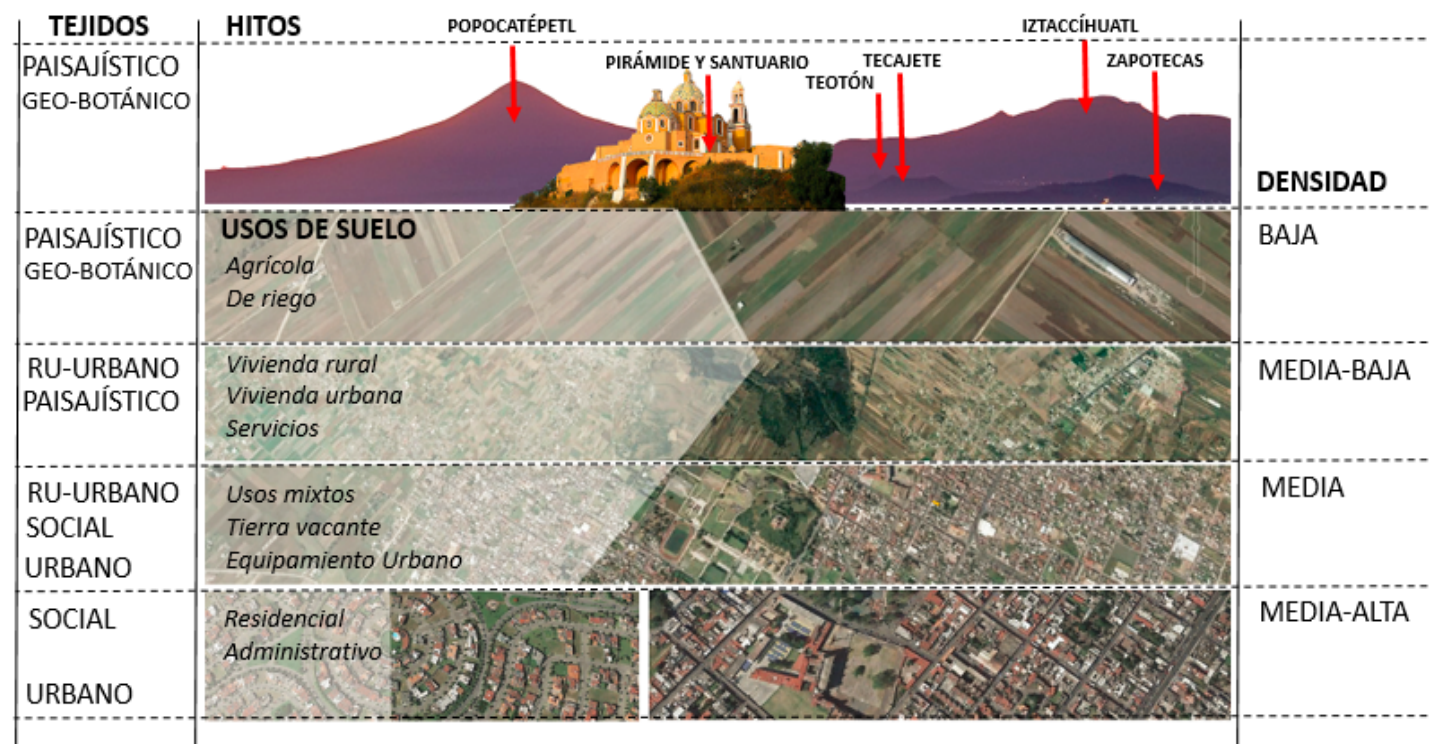

Cuadro 4. Propuesta de visualización del tejido territorial en Cholula. Fuente: M. Schumacher (2020) adaptado de Google Earth INEGI (2020).

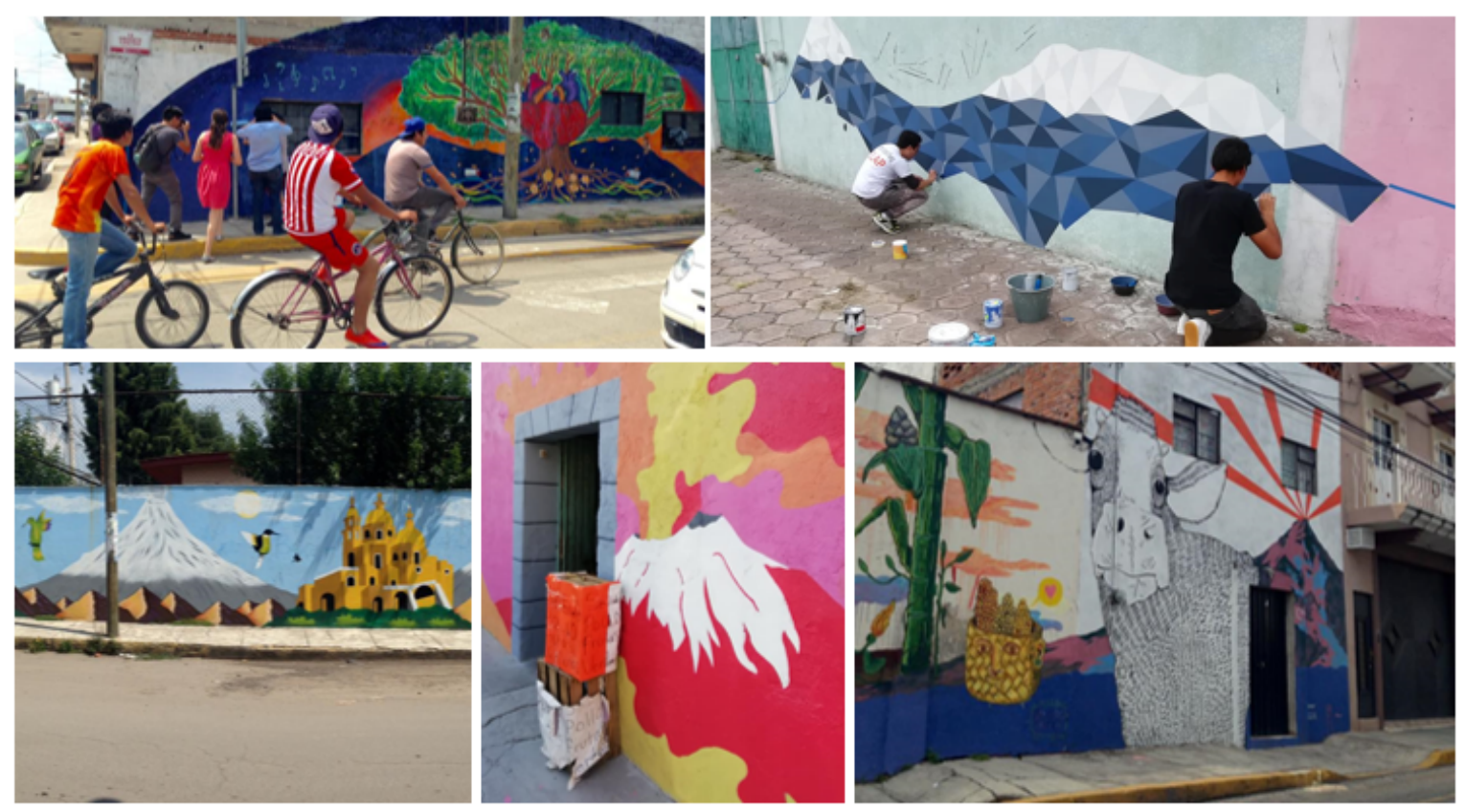

Figura 8. Imaginario colectivo de los hitos paisajísticos de Cholula representados en las fachadas de sus barrios. Proyectos Ciudad Mural Barrio de Santa María Xixitla (Colectivo Tomate) y \#TlatempaVivo Barrio de Jesús Tlatempa (Arquitectura UDLAP-Amealco Taller Colaborativo). Fuente: M. Schumacher $(2017,2018,2019)$.

Como ejemplo de plano medio en la Figura 8, se encuentran una serie de imágenes de dos barrios de Cholula (Santa María Xixitla y Jesús Tlatempa) donde el imaginario colectivo del paisaje se hace presente a través del arte urbano en sus 
fachadas. En este plano, la relación barrial (población-aspectos socioculturales) refuerza la identidad local de sus habitantes que utiliza el arte como medio de expresión de su colectividad. En este componente, la densidad media y los usos de suelo mixtos son mayoritarios, así como el patrimonio intangible y el sincretismo religioso que resguardan las mayordomías de cada barrio. Los recorridos que hacen los santos y la Virgen de los Remedios a través de los barrios, es reconocida por cada habitante en su organización socio-espacial, sus sonidos, sus colores y sus festividades.

Esto sería un buen ejemplo del por qué el Altépetl Cholula sigue vivo a pesar de la cultura hegemónica global. Con un alejamiento del plano medio a distante-individual, en los barrios se vive la relación biocultural con la tierra y el agradecimiento espiritual a las fuerzas de la naturaleza (religión) (Figura 9). Por ello, los volcanes y la pirámide se repiten en la mente y corazón de los habitantes de Cholula. Esto es una manifestación de la unidad hombre-paisaje en la narrativa humboldtiana; además que se puede afirmar que el paisaje ru-urbano de Cholula y sus expresiones espirituales van en contra de la estandarización de usos de suelo y la "dignificación" de espacios urbanos en las políticas de desarrollo.

Por último, un ejemplo de plano individual se aprecia en la Figura 10 donde una parcela de nopales o nopalera, expresa su análisis individualizado como producto agrícola relacionado con las siembras y el paisaje productivo de San Bernardino Tlaxcalancingo en San Andrés Cholula. La escala individual se vuelve compleja al entrelazarse con las capas urbanas que se traslapan sobre la supervivencia de usos de suelo rurales. Por ejemplo, es difícil estudiar las políticas de suelo en Cholula desde una óptica oficial sin considerar el componente socio-cultural, biocultural e intangible que ni un ningún programa de Pueblo Mágico considera en su complejidad. 

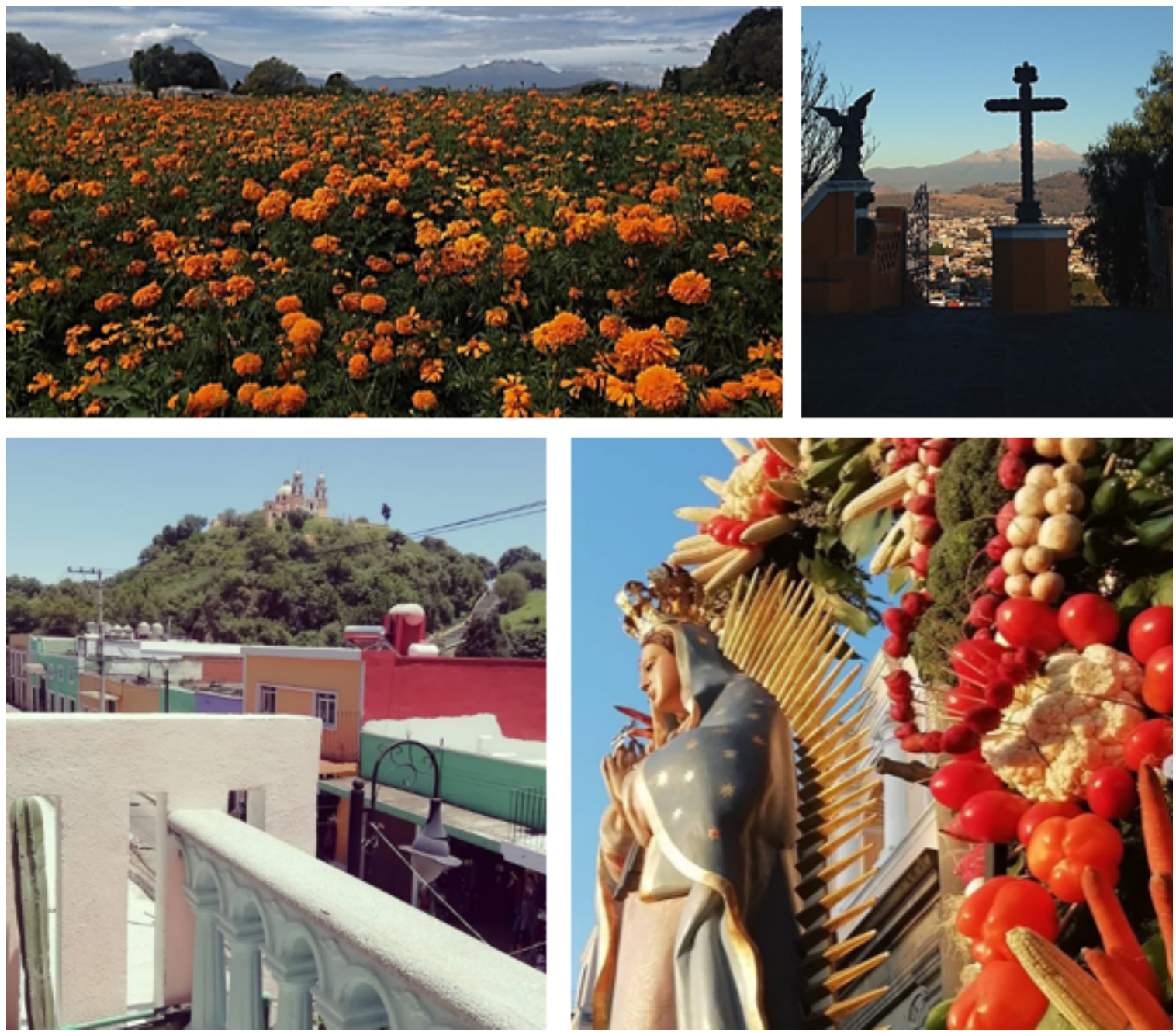

Figura 9. Imágenes que imponen respeto al visitante en Cholula. Diversas manifestaciones del paisaje y sus elementos bioculturales. Fuente: M. Schumacher (2019).

Dependiendo de la zona de estudio, el plano individual varía en sus elementos figurativos: nopal, maíz, maguey, huerta, hortaliza, milpa, terreno, solar, tierra vacante. Cada uno de estos elementos conforma el total del paisaje cholulteca cuando se mira desde el objeto individualizado a su máxima expresión que son los volcanes y el valle poblano.

Desde el plano individual se explican las asociaciones de los actores y habitantes de Cholula con su entorno paisajístico. En este caso, el diagrama de la Figura 11 expresa cómo es la asociación población-paisaje en función de un hito central que sería la Gran Pirámide de Cholula (Figura 9). En esta asociación, los barrios funcionan a través de la organización socio-espacial e intangible que son las mayordomías. 
Dentro de cada barrio, pueblo, junta auxiliar o colonia, se establecen físicamente los fraccionamientos (urbanizaciones cerradas) que por lo regular no están familiarizados con la función socio-espacial de los barrios, sin embargo, son actores clave en la transformación urbana del territorio cholulteca. No obstante, ambas unidades socio-espaciales no solo trabajan en torno a un hito central que es la Gran Pirámide, también los hitos periféricos como el paisaje natural serrano y volcánico terminan de enmarcar la totalidad de hitos, texturas y elementos compositivos del territorio de Cholula que se articula en el tejido urbano del área metropolitana de Puebla-Tlaxcala.

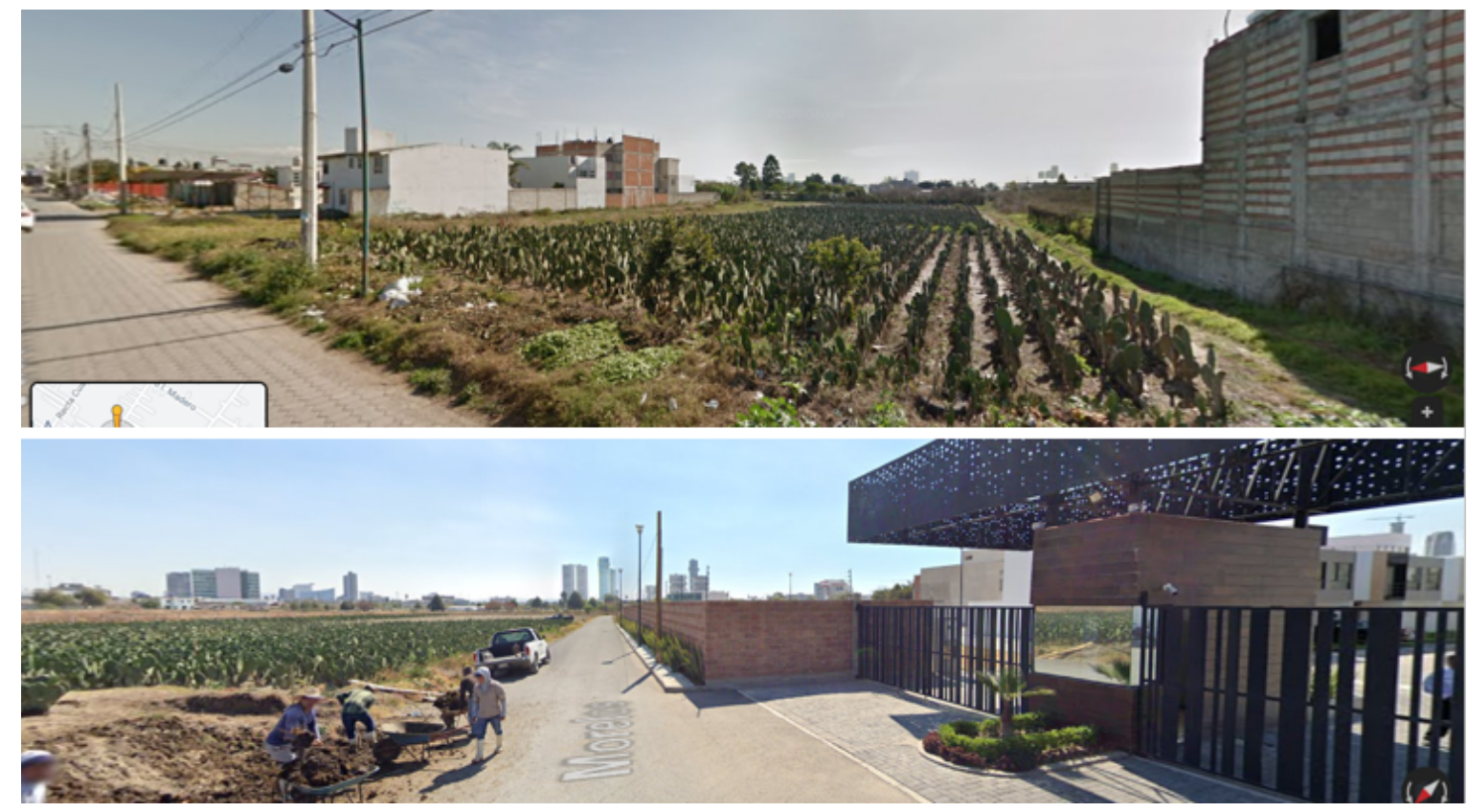

Figura 10. Cultivos de nopal o nopaleras en la junta auxiliar de San Bernardino Tlaxcalancingo, en San Andrés Cholula. Fuente: Street View Google Maps (2019). En ambas imágenes se puede apreciar que las parcelas están inmersas en un contexto urbano, en especial en la segunda se encuentra un nuevo fraccionamiento o urbanización privada y al fondo la Zona de Angelópolis, donde el crecimiento habitacional vertical y masivo se extiende sobre antiguos ejidos expropiados y la zona de nopaleras.

Sintetizando, la articulación del tejido ru-urbano y biocultural de Cholula es parte de la figuración y manifestación de un paisaje tangible e intangible, basado en el análisis figurativo humboldtiano. Con esto, es importante interpretar la historia del saber geográfico como la de la tensión entre razón cartográfica y logos, o lo que es lo mismo, entre el mapa y la narración (Farinelli), considerando que la gran ruptura humboldtiana fue convertir el paisaje, desde su inicial concepto estético en un concepto científico y más allá, en uno socio-ecológico; es decir, no ya un conjunto de elementos, sino una manera de verlos y de aprehenderlos (Garrido, Rebok, \& Puig-Samper, 2016b, p. 376). Si dicha interpretación la trasladamos a nuestro caso de estudio local, la ciudad sagrada de Cholula, la concepción figurativa del territorio se compone de diferentes texturas socio-territoriales, bioculturales y sus hitos que amarran la identidad de todo oriundo y residente del antiguo Altépetl. 


\section{Conclusiones}

En sus escritos, Humboldt expresó el respeto que inspiraba el paisaje del valle poblano, siendo una imagen que se encuentra tan arraigada en el imaginario colectivo histórico del Altiplano mexicano, que es casi imposible pensar en una pirámide sin su iglesia, en una zona arqueológica sin sus milpas, en una ciudad histórica sin sus volcanes, en una urbe metropolitana sin iglesias, cuetazos $^{12} \mathrm{y}$ festividades religiosas. Es así, que el sincretismo cholulteca no es exclusivo de la religión y la historia, su sincretismo se forja en una "unidad en la diversidad" (Schumacher, 2016) que integra un paisaje total, que invita al usuario a cambiar de escalas de planos para poder vivir la planta de maíz en la milpa más verde, el territorio ru-urbano inmerso en sus barrios antiguos, y los volcanes que abrazan con nubes y cenizas al Altépetl más vivo que tiene México.

Finalmente, es importante proporcionar información para la futura gestión del paisaje. Una historia detallada de su uso es esencial para evaluar los posibles impactos y consecuencias de la gestión futura de la ocupación del contexto, informada por el impacto de las actividades humanas en la conservación y restauración del paisaje y la biodiversidad (Rodríguez Bustos, 2013, pp.12-13). En estos términos, los conceptos humboldtianos y métodos de presentación infográficos de datos aquí presentados proporcionan un marco para el análisis de la interacción y las condiciones de coexistencia entre el paisaje, su biodiversidad y la comunidad humana.

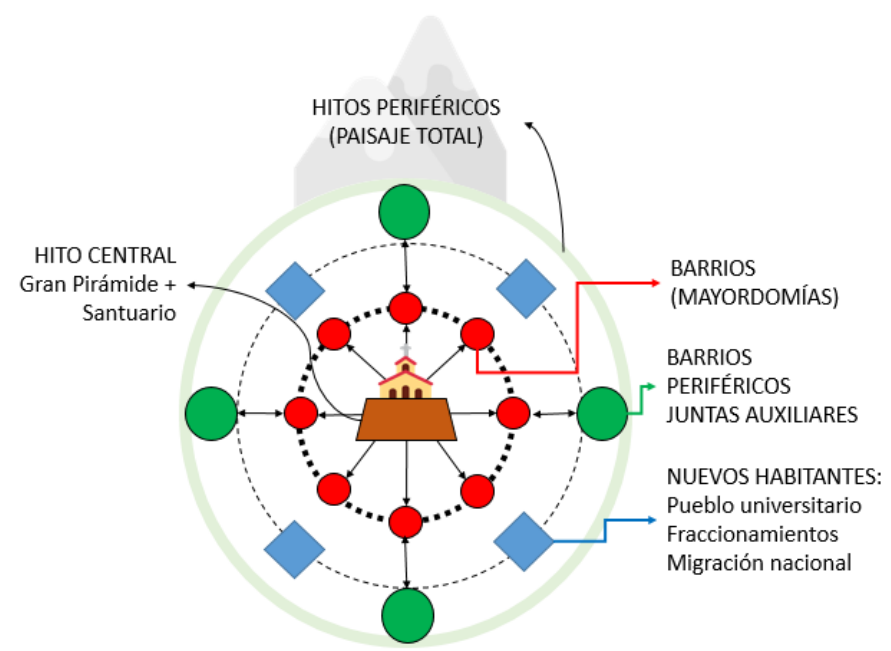

Figura 11. Asociación-función entre unidades socio-espaciales de Cholula y sus hitos paisajísticos. Fuente: adaptación de M. Schumacher (2020) de su tesis doctoral (2016).

\footnotetext{
12 Pirotecnia.
} 
Por todo lo anterior, este trabajo concluye que el espíritu humboldtiano del análisis paisajístico está ejemplificado en la región de Cholula, donde la conjunción de ciencia y arte se ve reflejada en el análisis de los diferentes planos que constituyen los tejidos socio-espaciales y ru-urbanos. Por ende, el saber experiencial de Humboldt en la figuración paisajística aplicado a Cholula "es un saber que relaciona la naturaleza con la cultura, que cobra sentido en la vida misma y que tiene como meta un estilo de vida que gran intensidad y, a la vez, reflexividad" (Ette, 2019, p.29). Por lo demás, la visión de Humboldt sobre el aprendizaje del territorio y el paisaje no es una especialidad de unos cuantos, sino todo lo contrario. Se puede y debe reconocer el territorio desde lo interdisciplinar y sus actores, comprendiendo así la totalidad de la unidad en el microcosmos de Humboldt.

\section{Referencias}

Antón, J. (2019). Humboldt, el genio romátnico que anticipó el cambio climático. El País. Recuperado de: https://elpais.com/elpais/2019/09/20/ideas/1568980684 909618.html

Ashwell, A. (2004). Cholula: su herencia en una red de agujeros. Elementos: Ciencia y Cultura, 11(55-56), 3-11. Recuperado de: https://elementos.buap.mx/directus/storage/uploads/00000002632.pdf

Barrio, M. Á. R. (2006). La representación del Tlachihualtepetl en el Códice de Cholula. El Mediterráneo y América: Actas Del XI Congreso de La Asociación Española de Americanistas (pp.813-822). Editora Regional de Murcia.

Bollnow, F. (1969). La espacialidad de la vida humana. Hombre y Espacio. Barcelona, España: Editorial Labor.

Bonfil Batalla, G. (1973). Cholula; la ciudad sagrada en la era industrial. Ciudad de México, México: UNAM.

Bürgi, M., \& Gimmi, U. (2007). Three objectives of historical ecology: the case of litter collecting in Central European forests. Landscape Ecology, 22(1), pp.77-87.

Calleja, A. C. A., Martínez, G. G., \& Soto, R. A. L. (2014). Cholula Viva y Digna. Los habitantes se unen en la lucha por conservar su Ciudad Sagrada, su tierra y nuestro patrimonio. Anuario Del Conflicto Social, (4). Recuperado de: https://doi.org/https://doi.org/10.1344/test.acs.2014.4.12272

Castree, N. (2005). Nature (Key Ideas in Geography). New York, Estados Unidos: Routledge.

Castree, N. (2013). Making sense of nature. New York, Estados Unidos: Routledge. 
Corberá Millán, M. V. (2014). Ciencia, naturaleza y paisaje en Alexander von Humboldt. Boletín de La Asociación de Geógrafos Españoles, 64, pp.37-64. Recuperado de: http://hdl.handle.net/10902/10148

Criado, M. Á. (2015). Un dibujo de Humboldt de hace 200 años prueba el cambio climático. El País. Recuperado de: https://elpais.com/elpais/2015/09/13/ciencia/1442177267_935134.html

Cuesta Domingo, M. (2008). Humboldt, viajero geógrafo. En S. Cuesta Domingo, M.,Rebok (Ed.), Alexander von Humboldt: estancia en España y viaje americano (pp. 19-68). Recuperado de: https://digital.csic.es/bitstream/10261/44122/1/HUMBOLDT_ACTAS.pdf.

De Humboldt, A. (1822). Ensayo político sobre el reino de la Nueva España (2014th ed.). Ciudad de México, México: Porrúa.

De Humboldt, Alexander; Bompland, A. (1826). Viaje a las regiones equinocciales del nuevo continente, hecho en 1799 hasta 1804 (tomo primero). Recuperado de:

http://cdigital.dgb.uanl.mx/la/1080018319 C/1080018319 T1/10800183 19_MA.PDF

Durán-Díaz, P., Armenta-Ramírez, A., Kurjenoja, A. K., \& Schumacher, M. (2020). Community Development through the Empowerment of Indigenous Women in Cuetzalan Del Progreso, Mexico. Land 2020, 9(5), p.163. https://doi.org/10.3390/LAND9050163

Ette, 0. (2019). Alexander von Humboldt y la globalización. Es saber en movimiento. Ciudad de México, México: El Colegio de México.

García Farrero, J. (2015). Sobre la expedición americana de Alexander von Humboldt (1769-1859): vinculación con la naturaleza, impulso nómada y realización de uno mismo. Espacio, Tiempo y Educación, 2(2), pp.313-333. Recuperado de: https://www.redalyc.org/articulo.oa?id=477447182015

Garrido, E., Rebok, S., \& Puig-Samper, M. Á. (2016). El arte al servicio de la ciencia: antecedentes artísticos para la impresión total del paisaje en Alexander von Humboldt. Dynamis, 36(2), pp.363-390. https://doi.org/10.4321/S0211-95362016000200006

Heidegger, M. (1997). Building, Dwelling, Living. In N. Leach (Ed.), Rethinking architecture : a reader in cultural theory (2005th ed., pp. 94-119). New York: Routledge. 
Heidegger, M. (2003). Observaciones relativas al arte, la plástica, el espacio: el arte y el espacio. Cuadernos de Cátedra Jorge Oteiza. Pamplona: Universidad

Pública de Navarra. Pamplona, España: Universidad Pública de Navarra.

Hernández-Flores, J. A., \& Martínez-Corona, B. (2011). Disputas del territorio rural: la Cholula prehispánica frente a la expansión de la Puebla colonial. Agricultura, Sociedad y Desarrollo, 8(2), pp.281-296.

Kraft, T. (2017). Das Naturgemälde im Werkkontext. En Alexander von Humboldts Naturgemälde der Tropen: das "Tableau physique des Andes et pays voisins"(1807). Recuperado de: https://www.avhumboldt.de/?p=11781

Leysinger, C. (2004). Maler, legacy and Mexico. En B. Erickson, R; M. Font y A. Schwartz (Ed.), Alexander von Humboldt. From the Americas to the Cosmos. International Symposium held at the Bildner Center for Western Hemisphere Studies 20, (pp. 311-324). Recuperado de: https://bildner.org/wp-content/uploads/2017/04/Alexander-von-Humbol dt.pdf

Minsch, J. (2008). Ciencia y estética: reflexiones en torno a la presentación científica y artística de la naturaleza en la obra de Alexander von Humboldt. En M. Cuesta Domingo, M. Rebok (Ed.), Alexander von Humboldt: estancia en España y viaje americano (pp. 280-297). Recuperado de: https://digital.csic.es/bitstream/10261/44122/1/HUMBOLDT_ACTAS.pdf

Moret, P., Muriel, P., Jaramillo, R., \& Dangles, O. (2019). Humboldt's Tableau Physique revisited. Proceedings of the National Academy of Sciences, 116(26), pp.12889-12894. https://doi.org/10.1073/PNAS.1904585116

Paredes Lara, A. F. (2004). Herencia y Sincretismo religioso en la ciudad de Cholula. Preservación de las tradiciones hasta nuestros días. (Universidad de las Américas Puebla). Recuperado de: http://catarina.udlap.mx/u dl a/tales/documentos/lco/paredes l af/

Pimentel, J. (2004). Cuadros y escrituras de la naturaleza. Asclepio, 56(2), pp.7-24.

Ponette-González, A. G., Marín-Spiotta, E., Brauman, K. A., Farley, K. A., Weathers, K. C., \& Young, K. R. (2013). Hydrologic Connectivity in the High-Elevation Tropics: Heterogeneous Responses to Land Change. BioScience, 64(2), pp.92-104. https://doi.org/10.1093/biosci/bit013

Rawding, C. (2017). 'Nature'and the legacy of Alexander von Humboldt. Geography, 102, pp.95-98. Recuperado de: http://geography.org.uk/Journals/Journals.asp?issueID=121

Reyes García, C. (1976). Altepetl: ciudad indígena. Cholula en el siglo XVI. UNAM. 
Rodríguez Bustos, L. A. (2013). Transformación del paisaje en la zona centro de la región Izta-Popo [1980-2013] Universidad Veracruzana. México. Recuperado de:

https://cdigital.uv.mx/bitstream/handle/123456789/37313/lauraaliciarod riguezbustos1.pdf?sequence $=1$ \&isAllowed $=\mathrm{y}$

Sampedro, J. (2016). Alexander von Humboldt, la ciencia al completo. El País. Recuperado de:

https://elpais.com/cultura/2016/09/09/babelia/1473420066_993651.ht $\underline{\mathrm{ml}}$

Schaffer, S. (1990). Genius in Romantic natural philosophy. Romanticism and the Sciences, pp.82-98.

Schumacher, M., Durán-Díaz, P., Kurjenoja, A. K., Gutiérrez-Juárez, E., \& González-Rivas, D. A. (2019). Evolution and Collapse of Ejidos in Mexico: How Far is Communal Land Used for Urban Development? https://doi.org/10.20944/PREPRINTS201907.0302.V1

Schumacher, M. (2016). Peri-urban development in Cholula, Mexico: Towards a socio-spatial management model. Lerhstuhl für Bodenordnung und Landentwicklung. Recuperado de: https://mediatum.ub.tum.de/doc/1276269/document.pdf

Sipmann, M. S. (2016). Sobre las huellas de Humboldt. Política Exterior, 30(174), pp.138-142. Recuperado de: http://www.jstor.org/stable/26450976

Wulf, A. (2016). La invención de la naturaleza: el nuevo mundo de Alexander von Humboldt. Taurus Penguin Random House. 